\title{
Detecting Diffusion Imaging constructive connectivity analysis for "What" stream Visual Pathways with correlations to Visual Agnosia
}

Ganesh Elumalai', Geethanjali Vinodhanand, Valencia Lasandra Camoya Brown ${ }^{1}$, Jessica Dasari ${ }^{1}$, Venkata Hari Krishna Kurra ${ }^{1}$, Kevin Andrew Douglas ${ }^{1}$, Nitya Akarsha Surya Venkata Ghanta', Kammila Joshna Naga Sudha ${ }^{1}$, Divya Singh ${ }^{1}$, Nitisha Tricia Dyal ${ }^{1}$, Pravitha Jose Sherly ${ }^{1}$, Ann Maria Joy ${ }^{1}$

${ }^{1}$ Team NeurON - Texila American University

\begin{abstract}
Visual perception is the ability to interpret the surrounding environment. A hypothetical "ventral" stream visual pathway explains how we perceive objects with respect to spatial orientation. The ventral stream fibers extend between "Visual cortex to Inferior temporal gyrus. The previous studies have failed to prove any indications on the -structural connectivity of this pathway. This study is designed to trace the existence of neural structural connectivity between "Visual cortex with Inferior temporal gyrus" using "Diffusion Tensor Imaging Tractography", which aims to correlate its functional importance with visual object perception.

The observational analysis used thirty-two healthy adults, ultra-high b-value and diffusion MRI datasets from an Open access research platform. The datasets range from both sexes, between 20-49 years, with mean age of 30.4 years. The confirmatory observational analysis process includes; datasets acquisition, pre-processing, processing, reconstruction, fiber tractography and analysis using software tools. All the datasets confirmed the fibre structural extension between, "Visual cortex to Inferior temporal gyrus in both the sexes may responsible for the visual perception of objects. This new fiber connectivity evidence justifies the structural relevance of visual perception impairments, such as visual object agnosia.
\end{abstract}

Keywords: Ventral Visual Stream, Dorsal Visual Stream, Visual Agnosia, Where visual pathways

\section{INTRODUCTION}


Past evidences which were proposed by most of the scientists that have published literature on ventral stream visual pathway states that it is a multisynaptic cortico-cortical connection. Ventral stream visual pathway is a cortical interconnection between the primary visual cortex (Brodmann area 17,18,19) and the inferior temporal lobe (Brodmann area 20), that helps in the identification of objects, colour interpretation, and face identification and recognition as mentioned by Mishkin and Ungerleider (1983) [1]. The three projections of the occipitotemporal interconnections are namely occipitotemporal-medialtemporal, occipitotemporal-orbitofrontal, and occipitotemporal-ventrolateral prefrontal pathways that are associated with exposure to long-term memory and the association of object-reward respectively (1990) [3]. Therefore, any damage to the inferior temporal lobe can lead to lack of recognition and memory to objects (1983) [1]. Similarly, in monkeys it is connected between striate, pre-striate and inferior temporal cortex (1983) [2]. Kravitz and Saleem stated that the occipitotemporal network which is especially for the ventral stream visual pathway is helpful for attentional, contextual, and feedback effects. There are six different cortical and subcortical systems where each system works on its own specialized behavioral, cognitive, or effective function. These six cortical systems collectively provide the most important purpose for the ventral stream visual pathway.

In Subcortical pathways, firstly: the unidirectional occipitotemporo-neostriatal pathway, second: the occipitotemporal-ventral striatum pathway and third: the occipitotemporal-amygdaloid pathway, whilst in cortical pathways, firstly: the occipitotemporal-medial temporal pathway, second: the occipitotemporal-orbitofrontal pathway and third: the occipitotemporal-ventrolateral prefrontal pathway. Anatomically, the ventral pathway is an internetwork for feed-forward and feedback projections which are unidirectional. Thus, it plays a major role in the perceptual identification, recognition of objects, spatial association, grasping and molding objects with the hands (1990) [3]. Some studies mention that there is white matter connection between the dorsal and ventral stream pathway (2015) [7]. Moreover, Polanen and Davere mentioned that the ventral stream receives information from the dorsal stream visual pathway and therefore refined the interpretation towards object's representation (2015) [8]. Additionally, Goodale and Milner proposed that the "what" pathway enables us to identify and grasp objects spatially oriented (1992) [4]. Severe bilateral damage to the occipitotemporal pathway that connects from the primary visual cortex to the inferior temporal lobe is in association with the "what" pathway hence can lead to Apperceptive agnosia which is the inability to recognize an object due to failure of perception. Apperceptive visual agnosia entails deficit of perceptual recognition of objects, differentiation of colors, faces, hand movements and gestures (2003) [9]. 
Apperceptive visual agnosia is mainly associated with damage to the association between the occipitotemporal interconnection that prevents the individual from identifying and recognizing objects and also framing their hand accordingly to hold or pick an object (1994) [5]. In the case of Alzheimer's in relation to visual agnosia, the damage to the occipitotemporal cortex leads to the absence of coordination and identification of objects thus, leading to a severe damage to the ventral stream visual pathway. (1999) [6].

\section{Materials and Methods}

The present study, designed to use the open access, ultra-high b-value, diffusion imaging datasets from Massachusetts General Hospital - US Consortium Human Connectome Project (MGH-USC HCP), which acquired from Thirty-two healthy adult participants (16 Males and 16 Females, between the ages of $20-49$ years). The imaging data is available to those who register and agree to the Open Access Data Use Terms.

\subsection{Participants}

Data was acquired from thirty- two healthy adults between the ages of 20 to 59 . A written consent was given by every participant and the procedure was carried out in accordance to the review board of their institution (MGH/HST) approval and procedures. All participants involved in this study, as the MGH-USC Adult Diffusion Dataset were scanned on the 3T CONNECTOM MRI scanner (see (Setsompop et al., 2013) for an overview) were housed at the Athinoula A. Martinos Center for Biomedical Imaging at MGH. A custom-made 64-channel phased array head coil was used for signal reception (Keil et al., 2013). No data regarding the thirty-two adults were saved in any other imaging modalities. Thirty-two healthy adults participated in this study (16 Females, 16 males, 20-49 years old; mean age $=30.4$ years old). A written consent was given by every participant and the procedure was carried out in accordance to the review board of Partners Healthcare by their institution (MGH/HST) approval and procedures. Participants' gender and age are available in the data sharing repository. Due to the limited sample size, there are some ages which we had only one participant. Given de-identification considerations, age information is provided in 5-year age bins. 


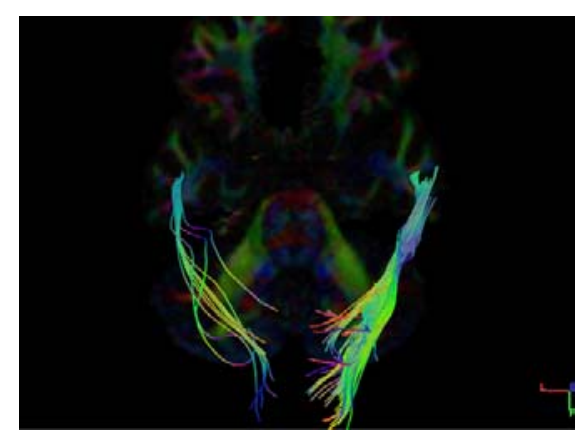

(Fig - 1) Female Bilateral Orientation of fibres

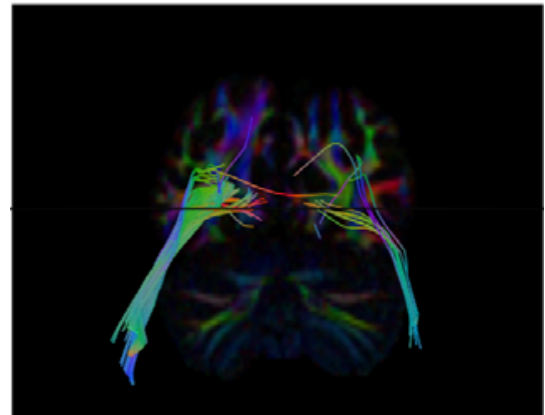

(Fig-2) Male Bilateral Orientation of fibres

\subsection{Data Acquisition}

The data was collected on the customized Siemens 3T Connectome scanner, which is a modified 3T Skyra system (MAGNETOM Skyra Siemens Healthcare), housed at the MGH/HST Athinoula A. Martinos Center for Biomedical Imaging. A 64-channel, tight-fitting brain array coil was used for data acquisition. dMRI data was acquired using a mono-polar Stejskal-Tanner pulsed gradient spin- echo echo planar imaging (EPI) sequence with Parallel imaging using Generalized Auto calibrating Partially Parallel Acquisition (GRAPPA). The Fast Low-angle Excitation Echo-planar Technique (FLEET) (Polimeni et al., 2015) was used for Auto-Calibration Signal (ACS) acquisitions to reduce motion sensitivity of the training data and improve stability and SNR of the GRAPPA reconstructions. The Simultaneous Multi-Slice (SMS; multi-band) technique (Feinberg et al., 2010; Feinberg and Setsompop, 2013; Setsompop et a1., 2012a; Setsompop et al., 2012b) has been shown to increase the time efficiency of diffusion imaging and was considered for this protocol, however at the point in the project timeline when data acquisition was to begin, the SMS method was not implemented in the EPI sequence featuring FLEET-ACS for GRAPPA. Because of the key benefits of in-plane acceleration for improved EPI data quality, such as lower effective echo spacing and hence mitigated EPI distortions and blurring, and also because of the longer image reconstruction times associated with SMS-EPI data, here data acquisition was performed without the use of SMS in favor of in-plane acceleration using FLEET-ACS and GRAPPA. (Acquisition of subsequent datasets including the Life Span dataset utilized a more newly implemented sequence combining SMS-EPI with FLEET-ACS and GRAPPA, see below.)

In each subject, dMRI data were collected with 4 different $b$-values (i.e., 4 shells): $1000 \mathrm{~s} / \mathrm{mm}^{2}$ (64 directions), $3000 \mathrm{~s} / \mathrm{mm}^{2}$ (64 directions), $5000 \mathrm{~s} / \mathrm{mm}^{2}$ (128 directions), and $10000 \mathrm{~s} / \mathrm{mm}^{2}$ (256 directions). Different $b$-values were achieved by varying the diffusion gradient amplitudes, while the gradient pulse duration $(\square)$ and diffusion time $(\square)$ were held constant. These $b$-values were 
chosen to provide some overlap with the HCP data from WU-Minn consortium, while at the same time push to the limit of diffusion weighting within the constraints of SNR and acquisition time. On determining the number of directions in each shell, in general, data with higher $b$-value was acquired with more DW directions to capture the increased ratio of high angular frequency components in the MR signal, and to compensate for the SNR loss due to increased diffusion weighting. Also, the number of directions in each shell was selected to meet the typical requirements of popular single shell and multi-shell analysis methods (e.g. q-ball imaging (Descoteaux et al., 2007; Tuch, 2004; Tuch et al., 2002; Tuch et al., 2003), spherical deconvolution (Anderson, 2005; Dell'Acqua et al., 2007; Tournier et al., 2004), ball and stick model (Behrens et al., 2007; Jbabdi et al., 2012), multi-shell q-ball imaging (Aganj et al., 2010; Yeh et al., 2010), diffusion propagator imaging (Descoteaux et al., 2009, 2011), etc.), and to keep the total acquisition time feasible in healthy control subjects.

The diffusion sensitizing direction sets were specifically designed so that the 64-direction set is a subset of the 128-direction set, which is again a subset of the 256-direction set. The initial 64 directions were calculated with the electro-static repulsion method (Caruyer et al., 2013; Jones et al., 1999). With these 64 directions fixed, another 64 directions were added as unknowns, and an optimized 128- direction set was calculated by adjusting the added 64 directions using electrostatic repulsion optimization. With these 128 directions fixed, the 256-direction set was generated using the same method. As such, all 4 shells share the same 64 directions; the $\mathrm{b}=5000 \mathrm{~s} / \mathrm{mm}^{2}$ shell and the $\mathrm{b}=10000 \mathrm{~s} / \mathrm{mm}^{2}$ shell share the same 128 directions.

During data acquisition, the diffusion sensitizing directions with approximately opposite polarities were played in pairs to counter-balance the eddy current effects induced by switching the diffusion weighting gradient on and off. Each run started with acquiring a non- DW image $(b=0)$, and one non-DW image was collected every $13 \mathrm{DW}$ images thereafter. Therefore 552 image volumes were collected in total, including $512 \mathrm{DW}$ and 40 non-DW volumes for each subject.

\subsection{DTI Data Pre-processing and Quality Control}

The MGH-USC HCP team completed their basic imaging data preprocessing, with software tools in Free surfer and FSL, which included (i.) Gradient nonlinearity correction, (ii.) Motion correction, (iii.) Eddy current correction, iv. b-vectors. All DTI data was corrected for gradient nonlinearity distortions offline (Glasser et al., 2013; Jovicich et al., 2006). Diffusion data was further corrected for head motion and eddy current artifacts. Specifically, the $b=0$ images interspersed throughout the diffusion scans were used to estimate bulk head movements with respect to the initial time point (the first $b=0$ image), where rigid transformation was calculated using the boundary-based registration tool in the Free Surfer package V5.3.0 (Greve and Fischl, 
2009). For each $b=0$ image, this transformation was then applied to itself and the following 13 diffusion weighted images to correct for head motion. Data of all $4 \mathrm{~b}$-values were concatenated (552 image volumes in total) and passed into the EDDY tool (Andersson et al., 2012) for eddy current distortion correction and residual head motion estimates. The rigid rotational components of the motion estimates were then used to adjust the diffusion gradient table for later data reconstruction purposes.

Both unprocessed and minimally pre-processed data are available for download in compressed NIfTI format. The measured gradient field nonlinearity coefficients are protected by Siemens as proprietary information. Because the gradient nonlinearity correction cannot be performed without this information, the unprocessed data provided had already been corrected for gradient nonlinearity distortions with no other pre-processing performed.

All the anatomical scans ( $\mathrm{T} 1 \mathrm{w}$ and $\mathrm{T} 2 \mathrm{w}$ ) were free from gross brain abnormalities as determined by a MGH trained physician. All MRI data (T1w, T2w and DW) went through the process of quality assessment by a MGH faculty member, $\mathrm{MGH}$ postdoctoral researcher and a MGH research assistant, all trained in neuroimaging in MGH. More specifically, each dataset was assessed by two raters, who viewed both the unprocessed and minimally pre-processed data volume by volume, and rated in terms of head movements, facial and ear mask coverage (to make sure that brain tissue was not masked off), and eddy current correction results. Finally, a comprehensive grade was given to determine whether a dataset had passed quality control.

\subsection{SUMMARY OF DATASETS:}

This data set was originally from the MGH-USC HCP team which released diffusion imaging and structural imaging data acquired from 32 young adults using the customized MGH Siemens 3T Connectome scanner, which has $300 \mathrm{mT} / \mathrm{m}$ maximum gradient strength for diffusion imaging. A multishell diffusion scheme was used, and the b-values were 1000, 3000, 5000 and $9950 \mathrm{~s} / \mathrm{mm} 2$. The number of diffusion sampling directions were 64, 64, 128, and 256. The in-plane resolution was $1.5 \mathrm{~mm}$. The slice thickness was $1.5 \mathrm{~mm}$.

\subsection{FIBER TRACTOGRAPHY:}

Fiber tractography is a very elegant method, which can used to delineate individual fiber tracts from diffusion images. The main process of study, uses the "DSI-Studio" software tools for i. Complete preprocessing, ii. Fiber tracking and iii. Analysis.

The imaging data processing, helps to convert the pre-processed raw data to src file format, which will be suitable for the further reconstruction process. The reconstruction of src files achieved through a software tool. It converts the .src imaging data to fib file format. Only 
the fib files are compatible for fiber tracking. To delineate individual fiber tracts from reconstructed diffusion images (.fib file), using a DSI studio software tools.

\section{RESULTS}

The fibres were traced, and identified in all 32 Diffusion MRI datasets for "Ventral" stream pathways, involved in visual spatial perception. Considering the reconstruction of fibres originated from the Primary Visual Cortex, a confirmatory observation of neural structural connectivity to the inferior temporal lobule was traced using the software DSI studio. All Diffusion MRI datasets are derived from the Human Connectome project and were analysed in a repeated manner with provided effects and tools in the option window in the software.

Observations on 32 MRI datasets, taking the age and sex into consideration the track analysis report retrieved. We performed t-test analysis for all 32 datasets selecting equal number of samples from both the group (16 males and 16 females) to check any difference in structural connections between the "Visual cortex (BA 18 \& 19) to Inferior Temporal Lobule (BA 20)". To validate the built atlas and its application among all the male and female datasets, we performed the t-test analysis of variance the for the following parameters (i) the number of tracts, (ii) volume of tracts, (iii) mean length of tracts and (iv) tracts standard deviation.

\section{i) Number of Tracts:}

The purpose of our study is deemed to find the neural structures extending between two cortices, connecting them from one end to another end. Fibre tracking uses diffusion tensor to track the fibres along the whole length starting from the seed to end region. The resolution of finding number of tracts helps us to correlate the actual function of ventral stream visual pathway - visual spatial perception with our present study. The greater number of fibres denotes that the patient has more efficiency in visually perceiving an object and a smaller number of tracts denotes that the patient might have less efficiency in perceiving an object or even a damage to that pathway may lead us to correlate clinically that the person might suffer from visual agnosia.
a) Male Right and Left Side
b) Female Right and Left side
c) Right side Male and Female
d) Left side Male and Female 


\section{a) Male Subjects Right \& Left}

The Fibres were traced and observed for neural structural connectivity on both right and left side in all sixteen healthy adult male datasets (Table1).

Dataset numbers 1006, 1007, 1011, 1013, 1014, 1016, 1027, 1029, 1031 shows greater number of tracts at right side. Dataset numbers 1008, 1009, 1015, 1022, 1027, 1028, 1030 shows a greater number of tracts on left side. Therefore, from the table given below, 9 datasets have more fibers on right and 7 datasets have more fibers on left but the variation in the count of fibers are more on right side (dataset number 1029).

Table 1: Number of Tracts Right and left in Male *

\begin{tabular}{|l|c|c|}
\hline Subject & $\begin{array}{c}\text { Number of Tracts } \\
\text { Right }\end{array}$ & $\begin{array}{c}\text { Number of tracts } \\
\text { Left }\end{array}$ \\
\hline 1006 & 304 & 1 \\
\hline 1007 & 47 & 6 \\
\hline 1008 & 32 & 133 \\
\hline 1009 & 12 & 21 \\
\hline 1011 & 80 & 11 \\
\hline 1013 & 243 & 17 \\
\hline 1014 & 25 & 1 \\
\hline 1015 & 3 & 1 \\
\hline 1016 & 10 & 2 \\
\hline 1022 & 3 & 55 \\
\hline 1025 & 78 & 48 \\
\hline 1027 & 221 & 272 \\
\hline 1028 & 4 & 54 \\
\hline 1029 & 367 & 45 \\
\hline 1030 & 9 & 45 \\
\hline 1031 & 105 & \\
\hline$*$-value is .236563, result is not significant at $p<.10$ & \\
\hline
\end{tabular}

When the results were statistically compared by performing independent $\mathrm{t}$ - test no significant

difference were seen between the number of tracts in right and left side of female subjects.

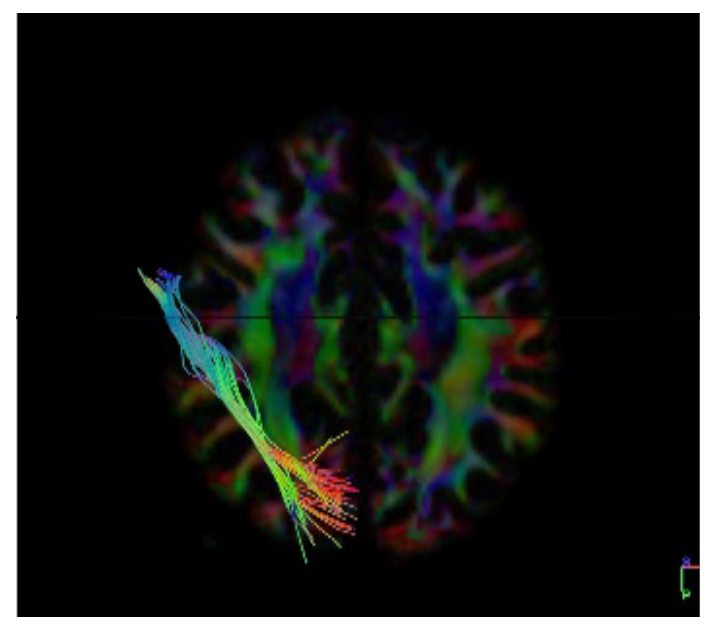

(Figure- 1) Axial Section Dataset subject - 1029 Male Right Side 


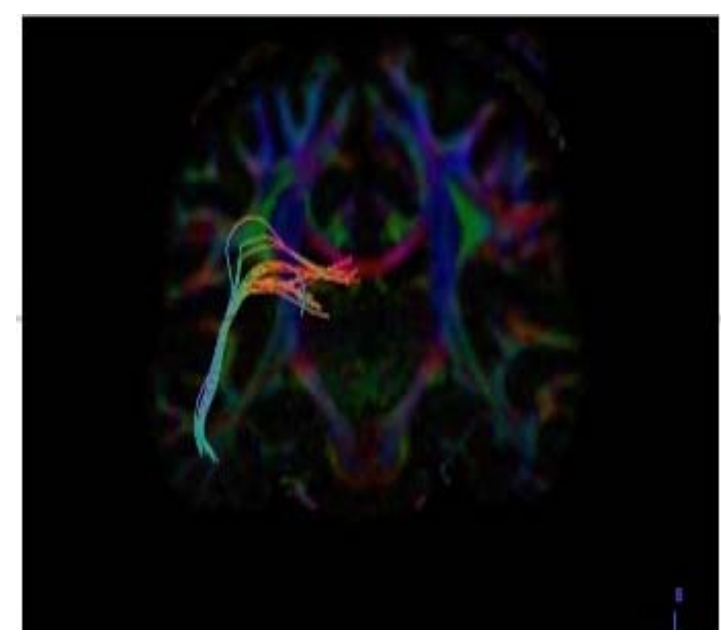

(Figure-2) Coronal Section Dataset subject - 1029 Male Left Side

\section{Graphical Representation:}

(Graph-1) plot in between number of tracts on $\mathrm{x}$-axis and 16 subjects in $\mathrm{y}$-axis to compare both left and right side of male datasets graphically. And we found that on an average right side is having a greater number of tracts when compared with left side in male subjects.

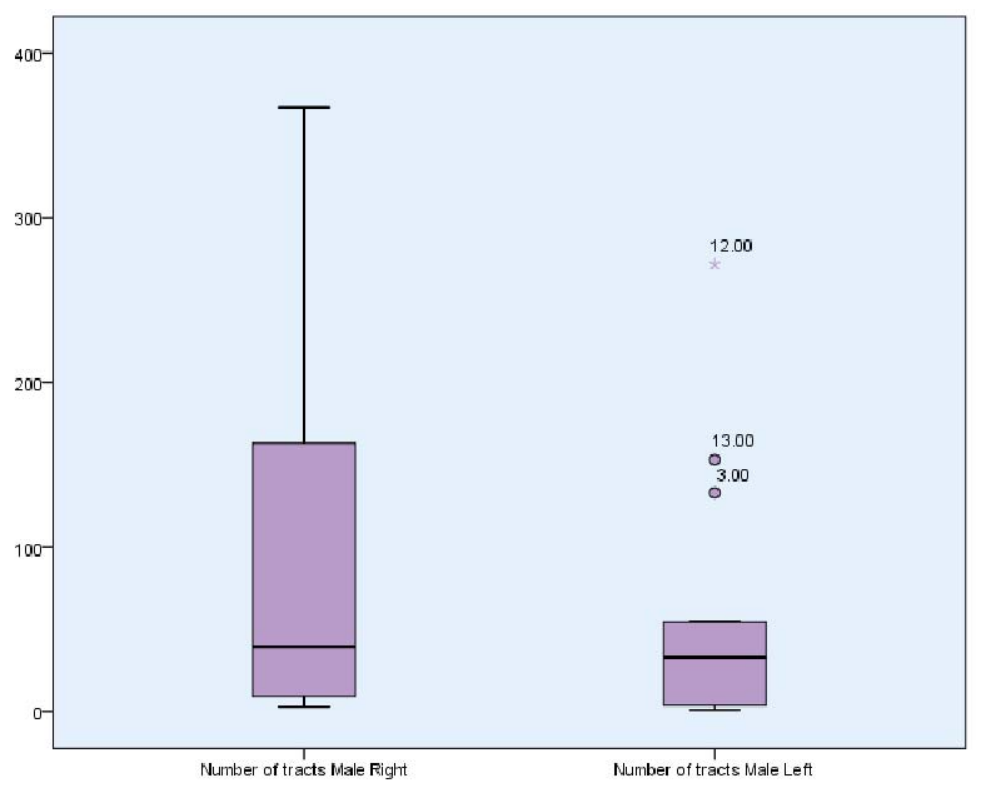

Graph-1: Comparison of Number of Tracts Right and left Ventral Stream Visual Pathway in Male Visual Pathway in Male

Normally in visual statistical learning when the right hemisphere is the dominant advantage of visual spatial integration and when the left hemisphere is also dominant, it is related to conceptual knowledge from patterns of covariation [92]. So, we conclude that there is no complete right side or complete left side dominance of ventral stream visual pathway in females, since if one side has less fibres the other side is balanced with its equalising fibres the same vice 
versa changes were seen if there are more fibres in one side, the other side is balanced with a less number of fibres.

\section{b) Female subjects Right \& Left}

The Fibres were traced and observed for neural structural connectivity on both right and left side in all sixteen healthy adult female datasets (Table2).

Dataset numbers 1002, 1012, 1019, 1021, 1023, 1024, 1033 shows greater number of tracts at right side. Dataset numbers 1001, 1003, 1004, 1005, 1010, 1026, 1035 shows greater number of tracts on left side. Datasets numbers 1017 and 1032 does not show much difference between the tracts. Therefore, from the table given below, 6 datasets have more fibers on right and 6 datasets have more fibers on left and no difference was seen in 2 datasets but the variation in the count of fibers are more in right side (dataset number 1021).

Table 2: Number of Tracts Right and Left in Female *

\begin{tabular}{|l|c|c|}
\hline Subject & $\begin{array}{c}\text { Number of Tracts } \\
\text { Right }\end{array}$ & $\begin{array}{c}\text { Number of Tracts } \\
\text { Left }\end{array}$ \\
\hline 1001 & 10 & 24 \\
\hline 1002 & 93 & 8 \\
\hline 1003 & 5 & 49 \\
\hline 1004 & 6 & 25 \\
\hline 1005 & 12 & 57 \\
\hline 1010 & 45 & 128 \\
\hline 1012 & 119 & 5 \\
\hline 1017 & 16 & 25 \\
\hline 1019 & 189 & 139 \\
\hline 1021 & 82 & 26 \\
\hline 1023 & 181 & 16 \\
\hline 1024 & 462 & 32 \\
\hline 1026 & 107 & 220 \\
\hline 1032 & 15 & 16 \\
\hline 1033 & 158 & 132 \\
\hline 1035 & 45 & 79 \\
\hline$*$ p value is .29355, result is not significant at $p$ & $<.10$ \\
\hline
\end{tabular}

When the results were statistically compared by performing independent t-test, no significant difference was seen between the number of tracts on right and left side of female subjects.

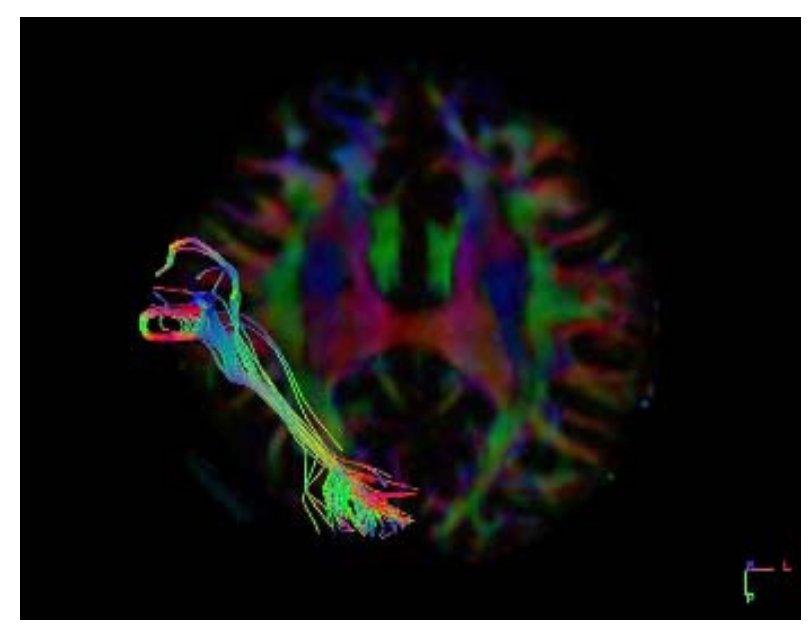


(Figure- 3) Axial Section Dataset subject - 1021 Female Right Side

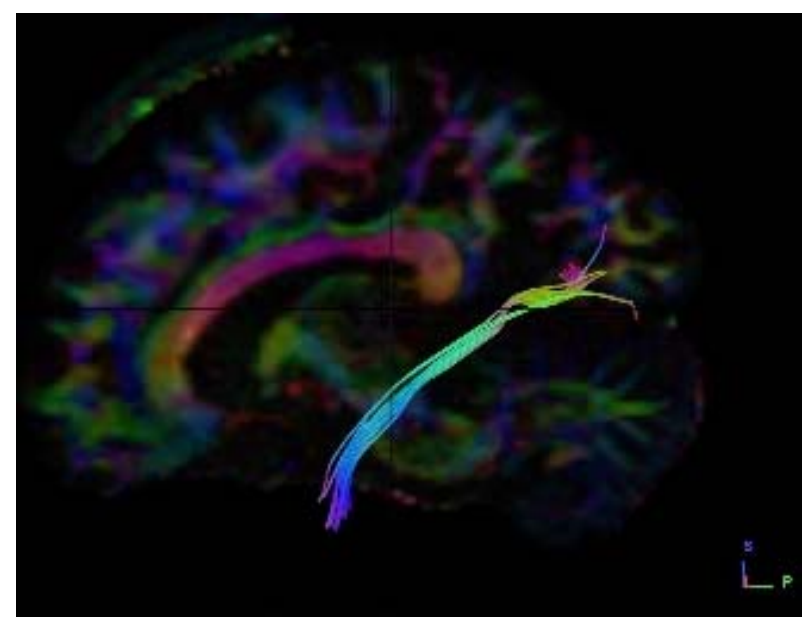

(Figure- 4) Sagittal Section Dataset subject - 1021 Female Left Side

\section{Graphical Representation:}

(Graph-2) plot showing number of tracts on $\mathrm{x}$-axis and 16 subjects on $\mathrm{y}$-axis to compare both left and right side of female datasets graphically. We found that on average, the right side is having a greater number of tracts when compared with left side in female subjects.

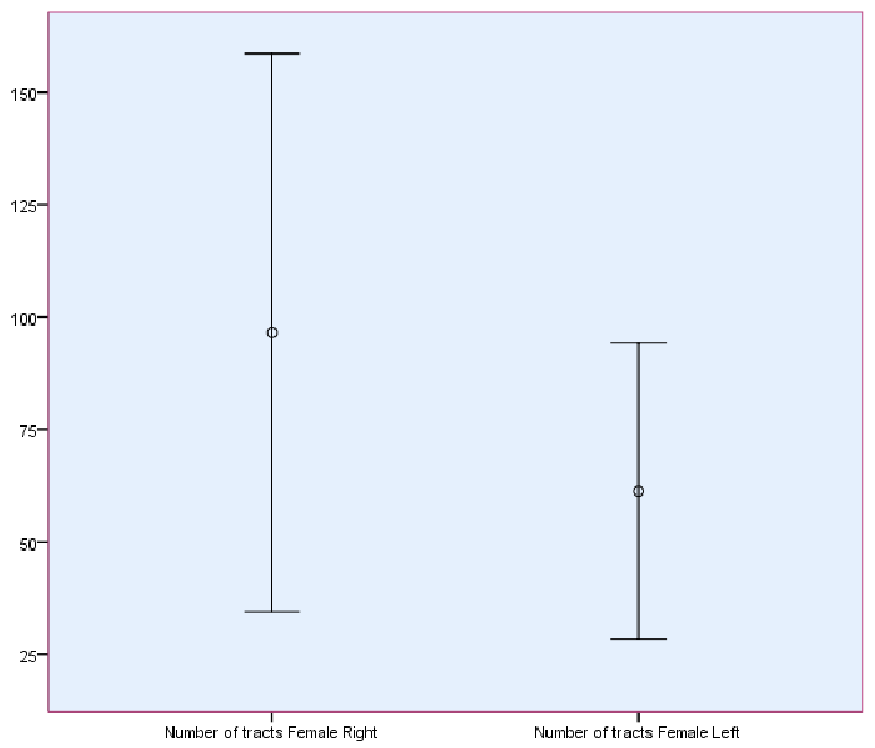

Graph-2: Comparison of Number of Tracts Right and left Ventral Stream Visual Pathway in Female So, we conclude that there is no complete right side or complete left side dominance of ventral stream visual pathway in females since if one side has less fibres, the other side is balanced with its equalising fibres and same vice versa changes were seen if there are more fibres on one side, the other side is balanced with a smaller number of fibres. 


\section{C) Right Side Both Male and Female Subjects}

The Fibres were traced and observed for neural structural connectivity on both right and left side in all sixteen healthy adult female datasets (Table 3 ).

Dataset numbers 1002, 1010, 1012, 1019, 1023, 1024, 1026, 1033, 1035 shows greater number of tracts in females. Dataset numbers 1006, 1007, 1008, 1011, 1013, 1025, 1027, 1029, 1031 shows a greater number of tracts in males. Therefore, from the table given below, 9 datasets have more fibers in male and 9 datasets have more fibers in female but the variation in the count of fibers are more seen in right side of male (dataset number 1024).

Table 3: Number of Tracts Right Female and Male *

\begin{tabular}{|l|c|c|c|}
\hline Subject & $\begin{array}{l}\text { Number of Tracts } \\
\text { in Female }\end{array}$ & Subjec & $\begin{array}{c}\text { Number of tracts } \\
\text { in Male }\end{array}$ \\
\hline 1001 & 10 & 1006 & 304 \\
\hline 1002 & 93 & 1007 & 47 \\
\hline 1003 & 5 & 1008 & 32 \\
\hline 1004 & 6 & 1009 & 12 \\
\hline 1005 & 12 & 1011 & 80 \\
\hline 1010 & 45 & 1013 & 243 \\
\hline 1012 & 119 & 1014 & 25 \\
\hline 1017 & 16 & 1015 & 3 \\
\hline 1019 & 189 & 1016 & 10 \\
\hline 1021 & 82 & 1022 & 3 \\
\hline 1023 & 181 & 1025 & 78 \\
\hline 1024 & 462 & 1027 & 221 \\
\hline 1026 & 107 & 1028 & 4 \\
\hline 1032 & 15 & 1029 & 367 \\
\hline 1033 & 158 & 1030 & 9 \\
\hline 1035 & 45 & 1031 & 105 \\
\hline$*$ p-value is 997628, result is not significant at $p<.10$ \\
\hline
\end{tabular}

When the results were statistically compared by performing independent t-test, no significant difference was seen between the number of tracts on right and left side of female subjects.

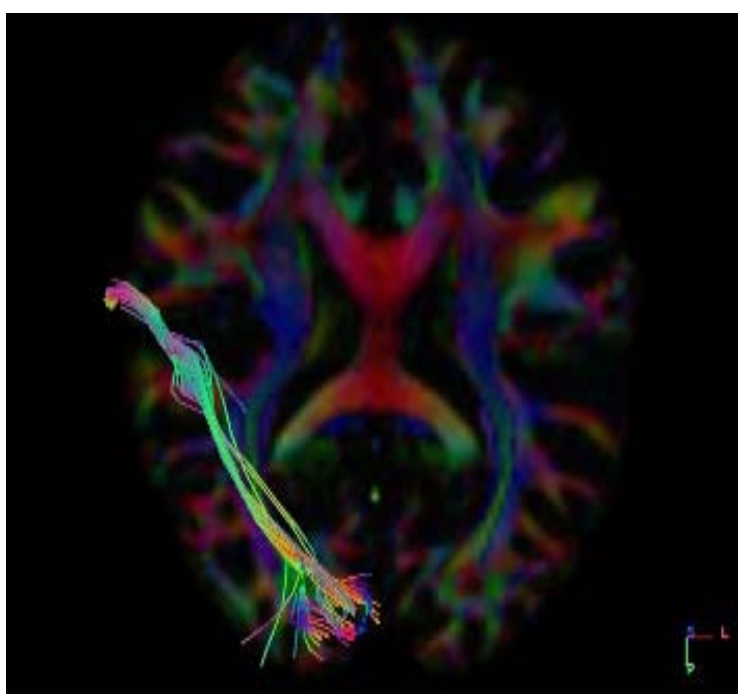


bioRxiv preprint doi: https://doi.org/10.1101/486639; this version posted December 4,2018 . The copyright holder for this preprint (which was not certified by peer review) is the author/funder, who has granted bioRxiv a license to display the preprint in perpetuity. It is made available under ACC-BY-ND 4.0 International license.

(Figure- 5) Axial Section Dataset subject - 1024 Male Right Side

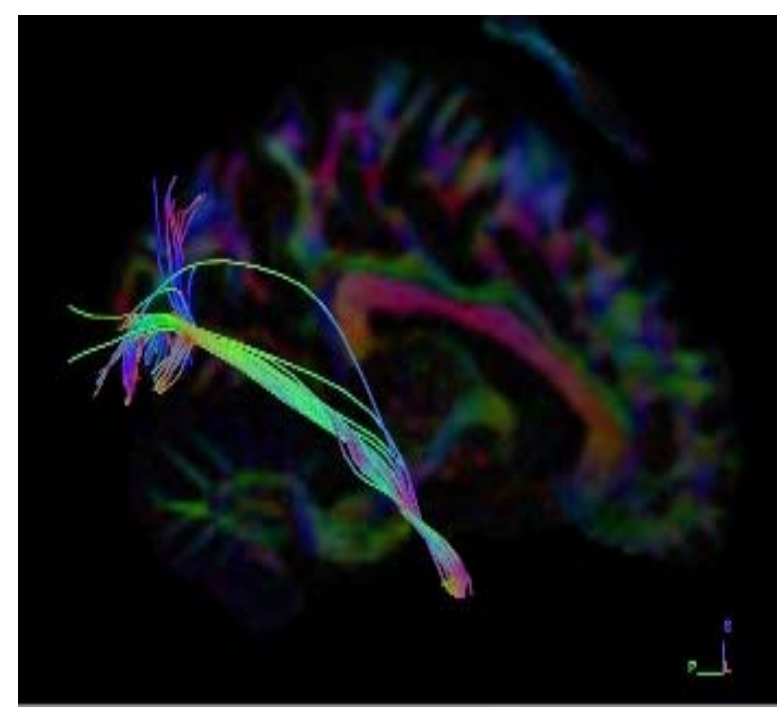

(Figure-6) Sagittal Section Dataset subject - 1024 Female Right Side

\section{Graphical Representation:}

(Graph-3) plot showing number of tracts on $\mathrm{x}$-axis and 16 subjects on $\mathrm{y}$-axis to compare right side of both male and female datasets graphically. Males typically outperform females on spatial tasks [93] and we found that on an average right side of males having a greater number of tracts when compared with left side in female subjects.

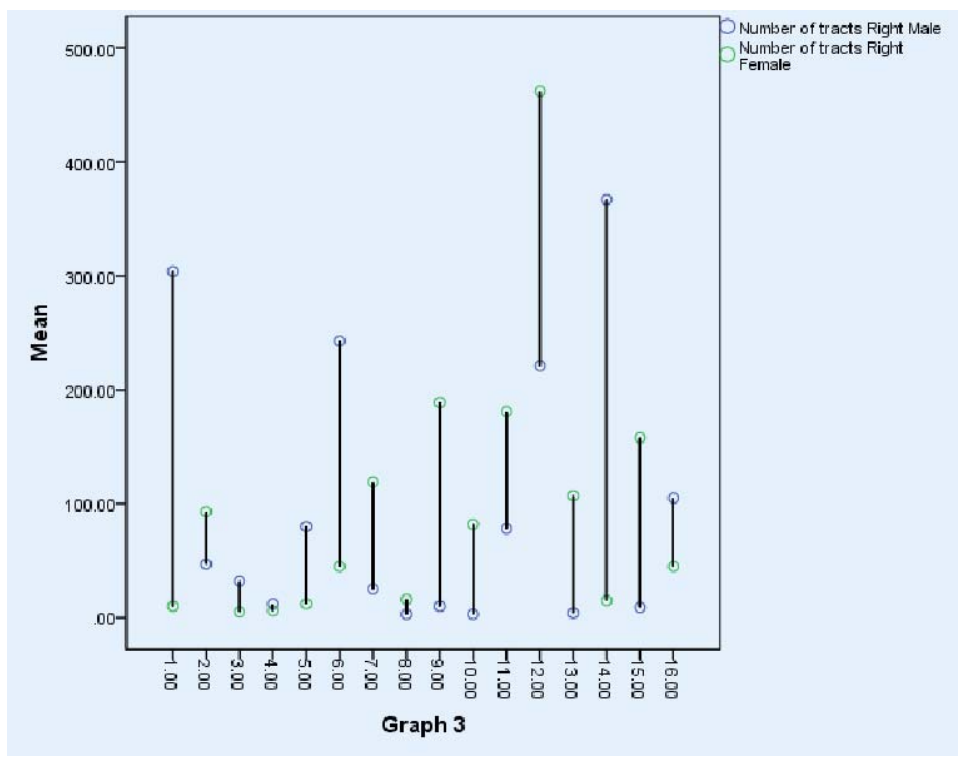

Graph-3: Comparison of Number of Tracts Right side Ventral Stream Visual Pathway in Female and Male 
So, we conclude that there is no right side or left side dominance of ventral stream visual pathway in females, since if one side has less fibres, the other side is balanced with its equalising fibres on the other side and same vice versa changes were seen if there are more fibres in one side, the other side is balanced with less number of fibres.

\section{d) Left Side Male and Female Subjects}

The Fibres were traced and observed for neural structural connectivity on both right and left side in all sixteen healthy adult male datasets (Table4). Dataset numbers 1003, 1005, 1010, $1019,1026,1033,1035$ shows greater number of tracts in female. Dataset numbers 1008, 1009, $1022,1025,1027,1028,1029,1030,1031$ shows a greater number of tracts in male. Therefore, from the table given below, 9 datasets have more fibers at male and 7 datasets have more fibers in but the variation in the count of fibers are more on left side of male (dataset number 1024).

Table 4: Number of Tracts Female and Male Left *

\begin{tabular}{|l|c|c|c|}
\hline Subject & $\begin{array}{c}\text { Number of } \\
\text { Tracts Female }\end{array}$ & Subject & $\begin{array}{c}\text { Number } \\
\text { of tracts Male }\end{array}$ \\
\hline 1001 & 24 & 1006 & 1 \\
\hline 1002 & 8 & 1007 & 6 \\
\hline 1003 & 49 & 1008 & 133 \\
\hline 1004 & 25 & 1009 & 21 \\
\hline 1005 & 57 & 1011 & 11 \\
\hline 1010 & 128 & 1013 & 17 \\
\hline 1012 & 5 & 1014 & 1 \\
\hline 1017 & 25 & 1015 & 1 \\
\hline 1019 & 139 & 1016 & 2 \\
\hline 1021 & 26 & 1022 & 55 \\
\hline 1023 & 16 & 1025 & 48 \\
\hline 1024 & 32 & 1027 & 272 \\
\hline 1026 & 220 & 1028 & 153 \\
\hline 1032 & 16 & 1029 & 54 \\
\hline 1033 & 132 & 1030 & 45 \\
\hline 1035 & 79 & 1031 & 45 \\
\hline$* p$-value is .765221, result is not significant at $p<.10$ \\
\hline
\end{tabular}


bioRxiv preprint doi: https://doi.org/10.1101/486639; this version posted December 4,2018 . The copyright holder for this preprint (which was not certified by peer review) is the author/funder, who has granted bioRxiv a license to display the preprint in perpetuity. It is made available under ACC-BY-ND 4.0 International license.

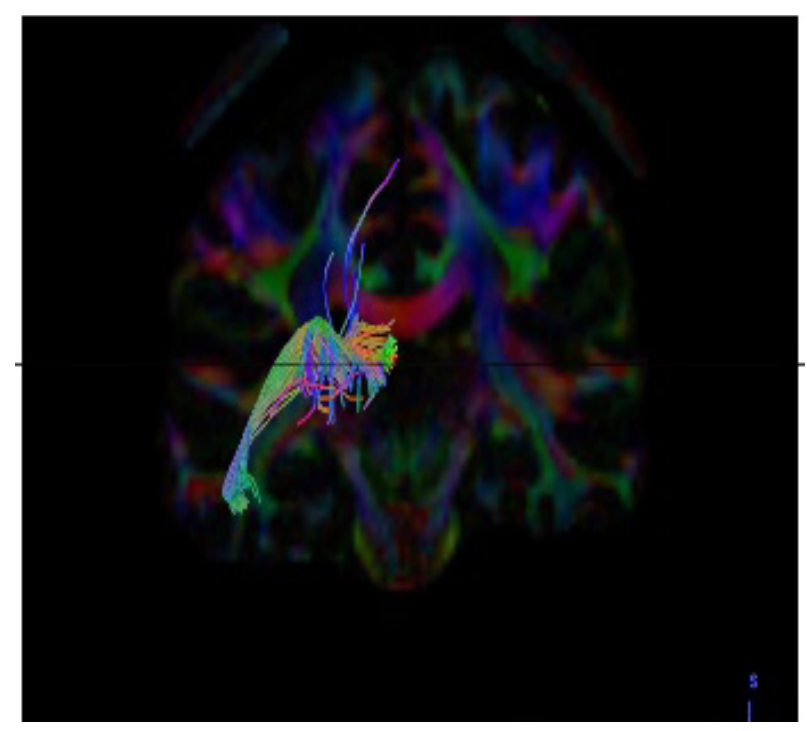

(Figure- 7) Coronal Section Dataset subject - 1024 Male Left Side

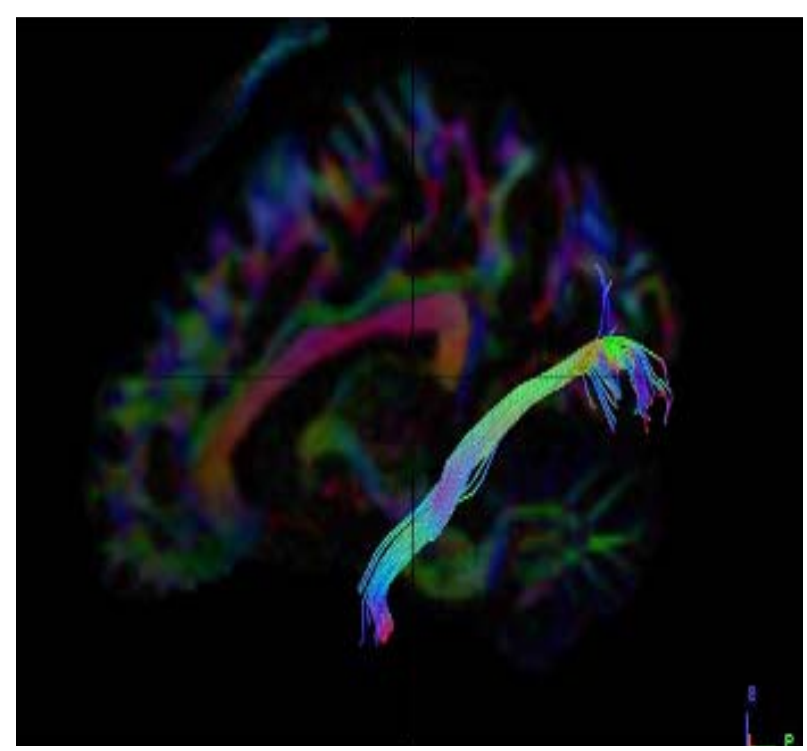

(Figure- 8) Sagittal Section Dataset subject - 1024 Female left Side

\section{Graphical Representation:}

(Graph-4) plot showing number of tracts on $\mathrm{x}$-axis and 16 subjects on $\mathrm{y}$-axis to compare left side of both male and female datasets graphically. Males typically outperform females on spatial tasks [93] and we found that on an average left side is having a greater number of tracts when compared with female subjects. 


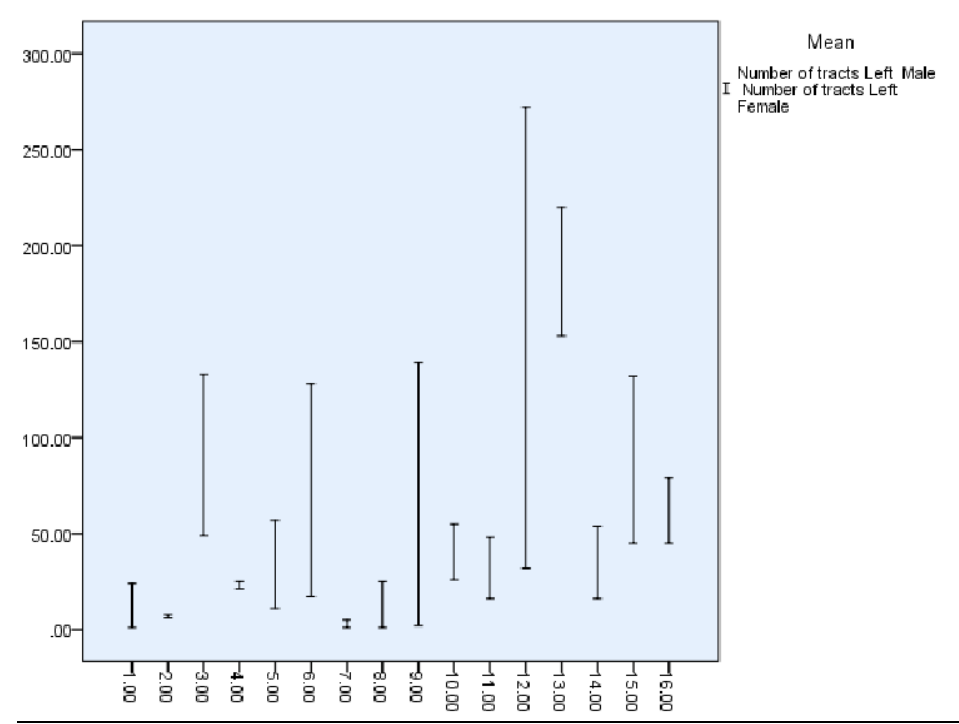

Graph-4: Comparison of Number of Tracts Left side Ventral Stream Visual Pathway in Female and

\section{Male}

So, we conclude that there is no right side or left side dominance of ventral stream visual pathway in females, since if one side has less fibres, the other side is balanced with its equalising fibres on the other side and same vice versa changes were seen if there are more fibres in one side the other side is balanced with a smaller number of fibres.

\section{ii) Volume of Tracts}

Tract volume is the total volume occupied by each fibre. Total volume is otherwise called the total number of voxels that were assigned as containing neural fibres. In correlation with our study, decrease or regression in the volume of the tracts might lead to clinical manifestations such as Visual Agnosia or Less efficiency of perceiving any object. The comparison of volume of Fibres is mostly done between the seed and the end region under four parameters;

a) Male Right and Left Side

b) Female Right and Left side

c) Right side Male and Female

d) Left side Male and Female

\section{a) Male Subjects Right \& Left}

The Fibres were traced and observed for neural structural connectivity on both right and left side in all sixteen healthy adult male datasets (Table 5).

Dataset number 1029 has the greatest volume right side and dataset number 1006 and 1031 has the least volume of tracts at right. Dataset number 1029 has greatest volume of tracts on left and dataset number 1014 has the least volume of tracts at left. Therefore, from the table given 
bioRxiv preprint doi: https://doi.org/10.1101/486639; this version posted December 4, 2018. The copyright holder for this preprint (which was not certified by peer review) is the author/funder, who has granted bioRxiv a license to display the preprint in perpetuity. It is made available under ACC-BY-ND 4.0 International license.

below, 7 datasets have more fibers at right and 9 datasets have more fibers at left but the variation in the count of fibers are more in left Side (dataset number 1029).

Table 5: Volume of Tracts male Right and Left*

\begin{tabular}{|l|c|c|}
\hline Subject & $\begin{array}{c}\text { Volume of Tracts } \\
\text { Right }\end{array}$ & $\begin{array}{c}\text { Volume of Tracts } \\
\text { Left }\end{array}$ \\
\hline 1006 & 1171.12 & 2838.37 \\
\hline 1007 & 4920.75 & 1218.37 \\
\hline 1008 & 1127.25 & 4941 \\
\hline 1009 & 1150.87 & 1782 \\
\hline 1011 & 1812.37 & 5629.5 \\
\hline 1013 & 4714.87 & 7668 \\
\hline 1014 & 6709.5 & 1090.13 \\
\hline 1015 & 2234.25 & 2652.75 \\
\hline 1016 & 5082.75 & 3526.88 \\
\hline 1022 & 6024.38 & 2794.5 \\
\hline 1025 & 8893.13 & 4131 \\
\hline 1027 & 4154.63 & 5686.88 \\
\hline 1028 & 1947.37 & 2737.12 \\
\hline 1029 & 6901.87 & 7374.37 \\
\hline 1030 & 4714.87 & 2838.37 \\
\hline 1031 & 1171.12 & 10 \\
\hline$* p-v a l u e$ is 293559, result is not significant at $p$ & $<$ \\
\hline
\end{tabular}

When the results were statistically compared by performing independent t-test, no significant difference was seen between the volume of tracts on right and left side of male subjects.

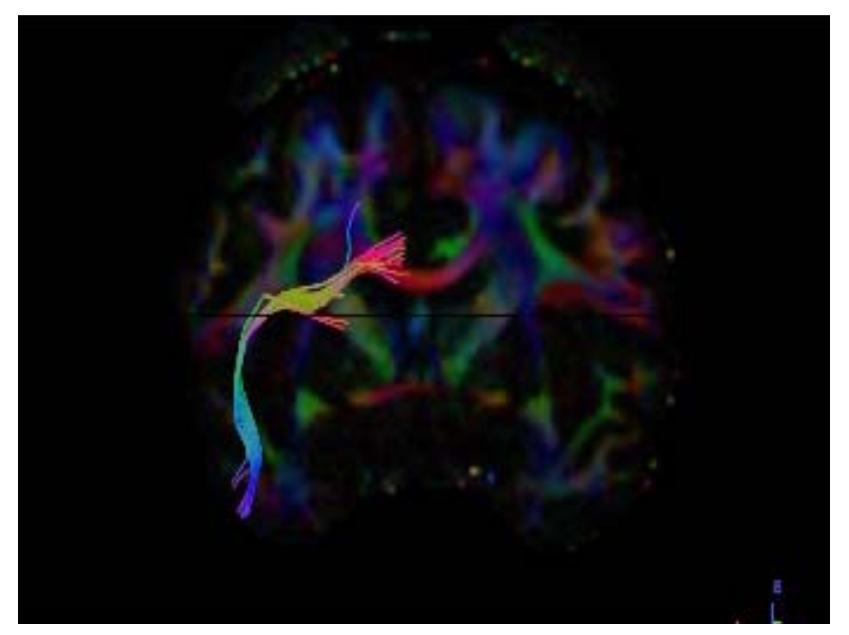

(Figure- 9) Coronal Section Dataset subject- 1029 Male Right Side 


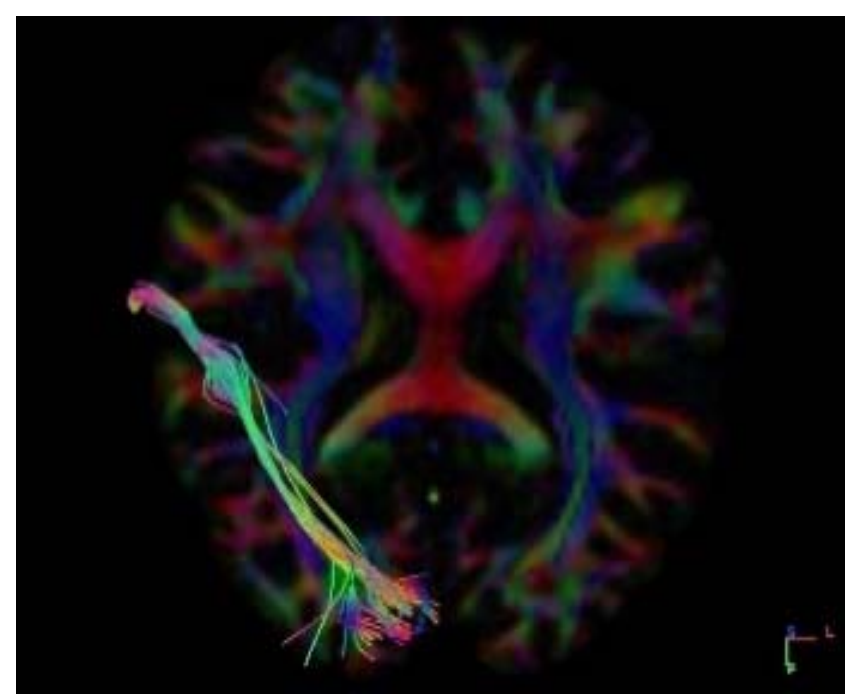

(Figure-10) Coronal Section Dataset subject- 1029 Female Right Side

\section{Graphical Representation:}

(Graph-5) plot showing number of tracts on $\mathrm{x}$-axis and 16 subjects on $\mathrm{y}$-axis to compare both left and right side of female datasets graphically. And we found that on an average left side is having a greater number of tracts when compared with right side in male subjects.

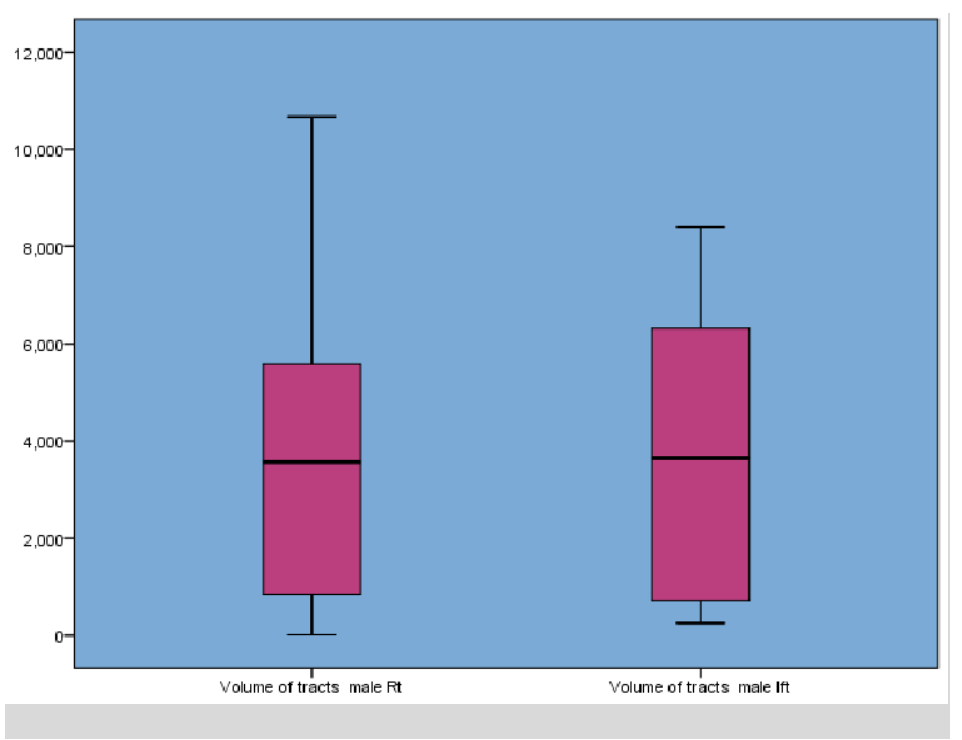

Graph-5: Comparison of Volume of Tracts Right \& Left Side of Ventral Stream Visual Pathway in Female

We conclude that there is no complete right side or complete left side dominance of ventral stream visual pathway in females, since if one side has less fibres, the other side is balanced with its equalising fibres and same vice versa changes were seen if there are more fibres in one side the other side is balanced with less number of fibres. 


\section{b) Right and Left side of Female subjects}

The Fibres were traced and observed for neural structural connectivity on both right and left side in all sixteen healthy adult female datasets (Table2).

Dataset numbers 1002, 1003, 1005, 1010, 1012, 1021, 1023, 1024 show greater volume of tracts at right side. Dataset numbers 1004, 1005, 1010, 1021, 1024, 1026, 1033, 1035 show a greater number of tracts on left side. Datasets number 1010 shows more volume of fibers in right side and 1033 shows least volume of fibers on the right side. Dataset number 1026 shows more volume of fibers in the left side and 1001 shows least fibers in the left side. Therefore, the variation in the volume of fibers are more on left side of female subject (dataset number 1021).

Table 6: Volume Of tracts Female Right and Left *

\begin{tabular}{|c|c|c|}
\hline Subject & $\begin{array}{c}\text { Volume of Tracts } \\
\text { Right }\end{array}$ & $\begin{array}{c}\text { Volume of Tracts } \\
\text { Left }\end{array}$ \\
\hline 1001 & 10661 & 256.5 \\
\hline 1002 & 4755.37 & 988.875 \\
\hline 1003 & 5410.12 & 7830 \\
\hline 1004 & 1876.5 & 2446.877 \\
\hline 1005 & 5403.38 & 2139.75 \\
\hline 1010 & 10671.7 & 2143.13 \\
\hline 1012 & 2379.37 & 286.875 \\
\hline 1017 & 658.125 & 313.875 \\
\hline 1019 & 1674 & 455.625 \\
\hline 1021 & 529.875 & 5892.75 \\
\hline 1023 & 5511.38 & 4846.5 \\
\hline 1024 & 8464.5 & 8224.87 \\
\hline 1026 & 732.375 & 8403.75 \\
\hline 1032 & 9.19767 & 6736.5 \\
\hline 1033 & 938.25 & 4944.38 \\
\hline 1035 & 5653.13 & 4944.38 \\
\hline$* p-v a l u e$ is .293559, result is not significant at $p<.10$ \\
\hline
\end{tabular}

When the results were statistically compared by performing independent t-test, no significant difference was seen between the volume of tracts in right and left side of female subjects.

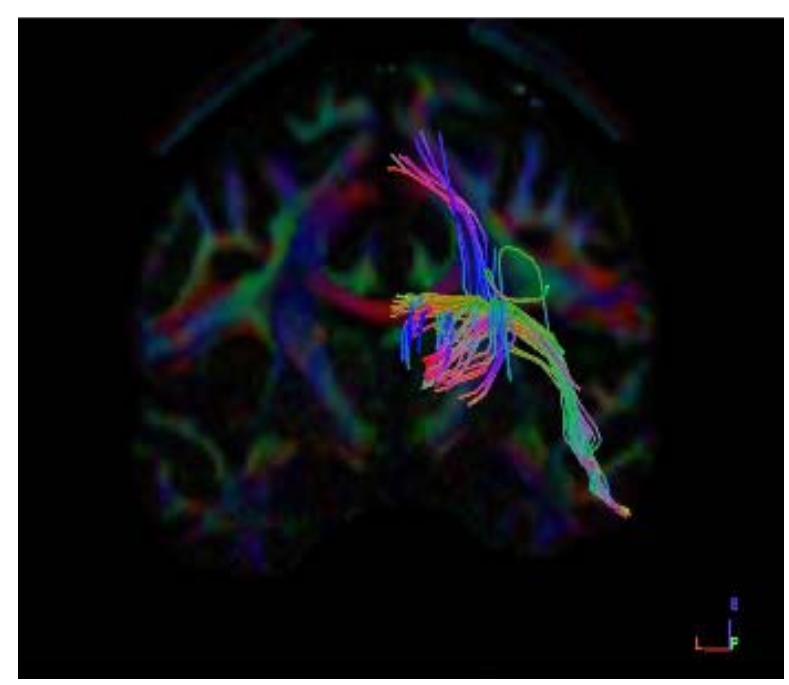

(Figure-11) Coronal Section Dataset subject- 1021 Female Right Side 


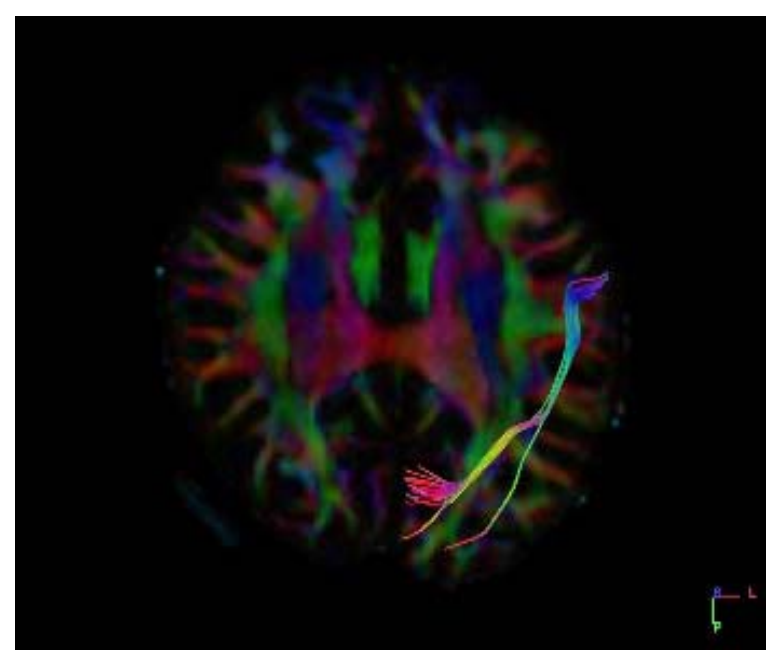

(Figure-12) Coronal Section Dataset subject- 1021 Female Left Side

\section{Graphical Representation:}

(Graph-6) plot showing Volume of tracts on $\mathrm{x}$-axis and 16 subjects on $\mathrm{y}$-axis to compare both left and right side of female datasets graphically. We found that on average, the left side is having a greater number of tracts when compared with right side in female subjects.

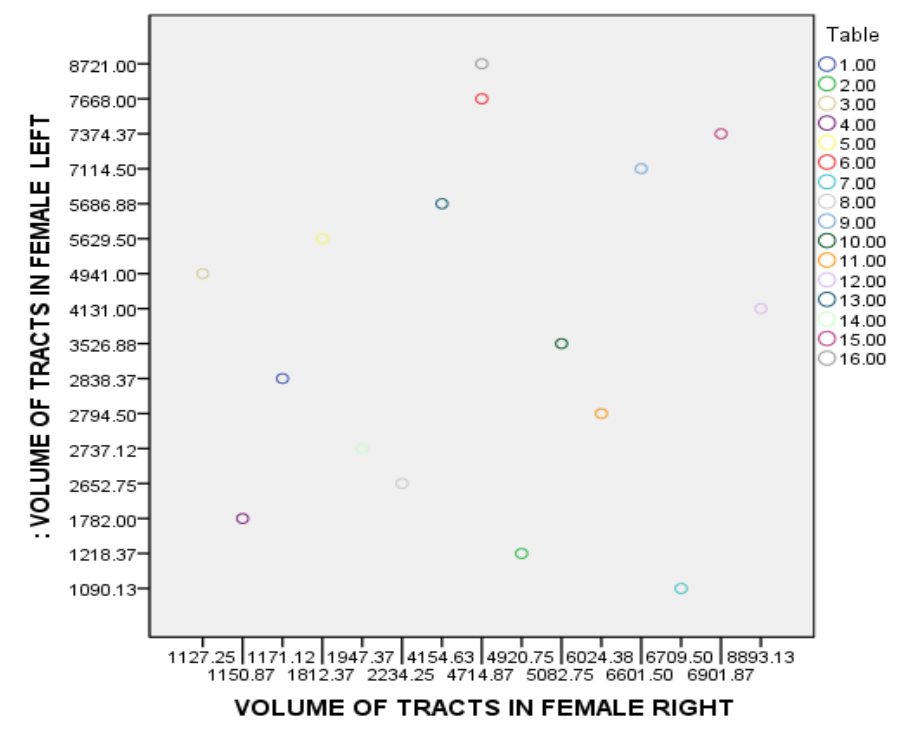

Graph-6: Comparison of Volume of Tracts Right \& Left side of Ventral Stream Visual Pathway in Male

We conclude that there is no complete right side or complete left side dominance of ventral stream visual pathway in females, since if one side has less fibres the other side is balanced with its equalising fibres and same vice versa changes were seen if there are more fibres in one side, the other side is balanced with a smaller number of fibres. 


\section{C) Right Side Both Male and Female Subjects}

The Fibres were traced and observed for neural structural connectivity on both right and left side in all sixteen healthy adult female datasets (Table 7 ).

Dataset numbers 1002, 1010, 1012, 1019, 1023, 1024, 1026, 1033, 1035 shows greater volume of tracts on female. Dataset numbers 1006, 1007, 1008, 1011, 1013, 1025, 1027, 1029, 1031 shows a greater number of tracts on male. Therefore, from the table given below, 9 datasets have more fibers in male and 9 datasets have more fibers in female but the variation in the count of fibers are more seen in right Side of male (dataset number 1024).

Table 7: Volume of tracts in Female and Male Right *

\begin{tabular}{|c|c|c|c|}
\hline Subject & $\begin{array}{c}\text { Volume of } \\
\text { Tracts Female }\end{array}$ & Subject & $\begin{array}{c}\text { Volum } \\
\text { ef tracts } \\
\text { Male }\end{array}$ \\
\hline 1001 & 1171.12 & 1006 & 10661 \\
\hline 1002 & 4920.75 & 1007 & 4755.37 \\
\hline 1003 & 1127.25 & 1008 & 5410.12 \\
\hline 1004 & 1150.87 & 1009 & 1876.5 \\
\hline 1005 & 1812.37 & 1011 & 5403.38 \\
\hline 1010 & 4714.87 & 1013 & 10671.7 \\
\hline 1012 & 6709.5 & 1014 & 2379.37 \\
\hline 1017 & 2234.25 & 1015 & 658.125 \\
\hline 1019 & 6601.5 & 1016 & 1674 \\
\hline 1021 & 5082.75 & 1022 & 529.875 \\
\hline 1023 & 6024.38 & 1025 & 5511.38 \\
\hline 1024 & 8893.13 & 1027 & 8464.5 \\
\hline 1026 & 4154.63 & 1028 & 732.375 \\
\hline 1032 & 1947.37 & 1029 & 9.19767 \\
\hline 1033 & 6901.87 & 1030 & 938.25 \\
\hline 1035 & 4714.87 & 1031 & 5653.13 \\
\hline$* p-v a l u e$ is .870655, result is not significant at $p<.10$ \\
\hline
\end{tabular}

When the results were statistically compared by performing independent t-test, no significant difference were seen between the volume of tracts in right side of male and female subjects.

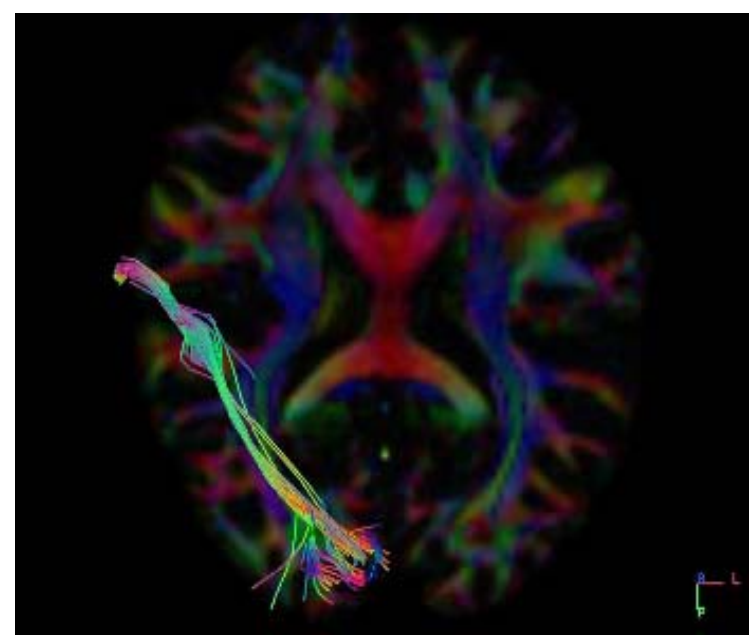


(Fig 13) Axial Section Dataset subject - 1024 Female right Side

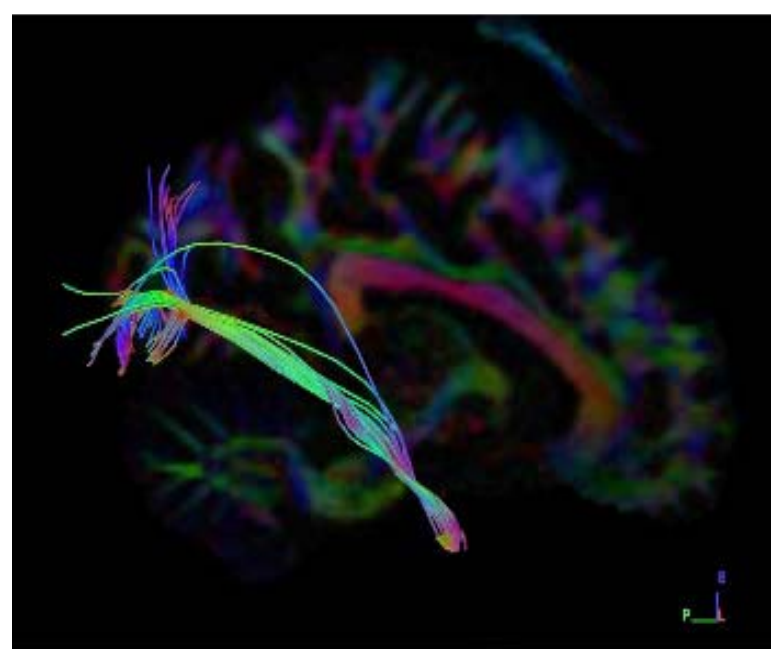

(Fig 14) Sagittal section Dataset subject -1024 Male ight side

\section{Graphical Representation:}

(Graph-7) plot showing Volume of tracts on $\mathrm{x}$-axis and 16 subjects on $\mathrm{y}$-axis to compare both left and right side of female datasets graphically. We found that on average, the right side is having a greater number of tracts when compared with right-side of both male and female subjects.

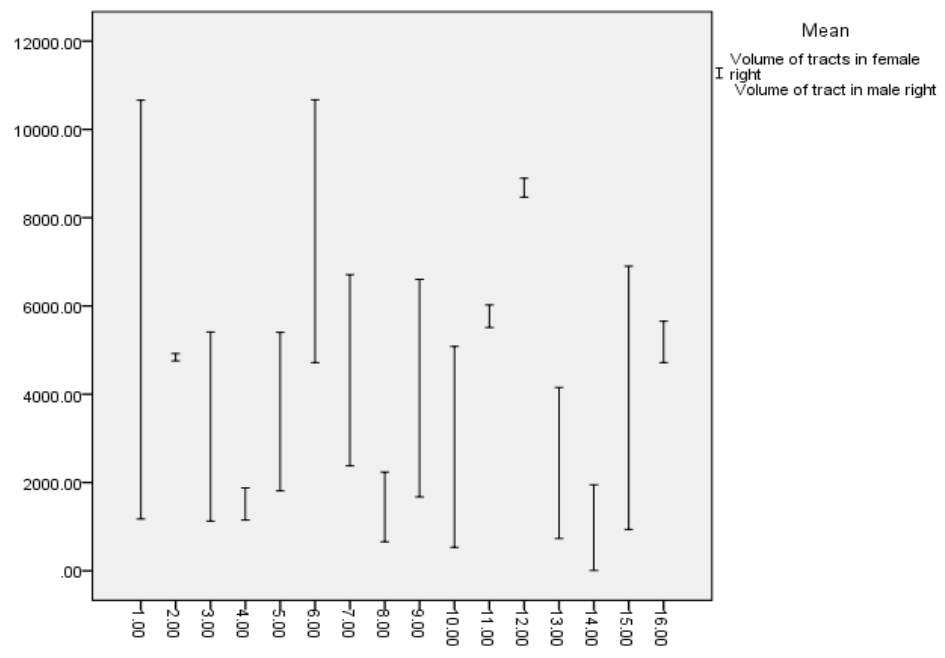

Graph-7: Comparison of Volume of Tracts in Right side of female and male Ventral Stream

\section{Visual Pathway}

We conclude that no complete right-side dominance of ventral stream visual pathway is seen in male and female subjects, since if one side has less fibres the other side is balanced with its equalising fibres. 


\section{d) Left Side Male and Female Subjects}

The Fibres were traced and observed for neural structural connectivity on both right and left side in all sixteen healthy adult male datasets (Table-8).

Dataset numbers 1003, 1005, 1010, 1019, 1026, 1033, 1035 shows greater Volume of tracts in females. Dataset numbers 1008, 1009, 1022, 1025, 1027, 1028, 1029, 1030, 1031 shows a greater number of tracts in male. Therefore, from the table given below, 9 datasets have more fibers at male and 7 datasets have more fibers but the variation in the count of fibers are more in left side of male (dataset number 1024).

Table 8: Volume of tracts in Female and Male Left *

\begin{tabular}{|c|c|c|c|}
\hline Subject & $\begin{array}{l}\text { Volume of Tracts } \\
\text { Female }\end{array}$ & Subject & $\begin{array}{l}\text { Volume } \\
\text { tracts Male }\end{array}$ \\
\hline 1001 & 2838.37 & 1006 & 256.5 \\
\hline 1002 & 1218.37 & 1007 & 988.875 \\
\hline 1003 & 4941 & 1008 & 7830 \\
\hline 1004 & 1782 & 1009 & 2446.877 \\
\hline 1005 & 5629.5 & 1011 & 2139.75 \\
\hline 1010 & 7668 & 1013 & 2143.13 \\
\hline 1012 & 1090.13 & 1014 & 286.875 \\
\hline 1017 & 2652.75 & 1015 & 313.875 \\
\hline 1019 & 7114.5 & 1016 & 455.625 \\
\hline 1021 & 3526.88 & 1022 & 5892.75 \\
\hline 1023 & 2794.5 & 1025 & 4846.5 \\
\hline 1024 & 4131 & 1027 & 8224.87 \\
\hline 1026 & 5686.88 & 1028 & 8403.75 \\
\hline 1032 & 2737.12 & 1029 & 6736.5 \\
\hline 1033 & 7374.37 & 1030 & 4944.38 \\
\hline 1035 & 8721 & 1031 & 4944.38 \\
\hline
\end{tabular}

When the results were statistically compared by performing independent t-test no significant difference was seen between the volume of tracts in left side of male and female subjects. 
bioRxiv preprint doi: https://doi.org/10.1101/486639; this version posted December 4,2018 . The copyright holder for this preprint (which was not certified by peer review) is the author/funder, who has granted bioRxiv a license to display the preprint in perpetuity. It is made available under ACC-BY-ND 4.0 International license.

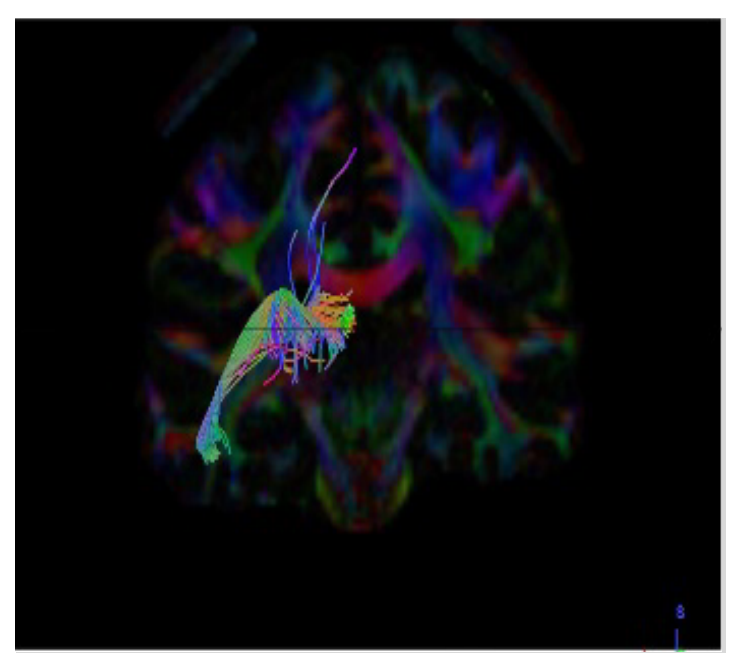

(Fig 16 ) Coronal section Dataset Subject -1028 Male left side

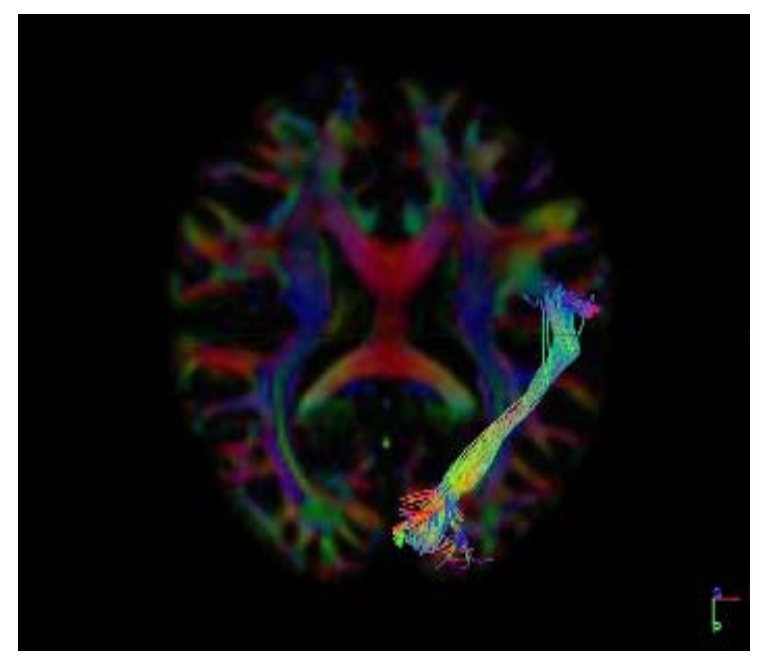

(Fig 17) Axial Section Dataset Subject - 1026 Female left side

\section{Graphical Representation:}

(Graph-8) plot showing Volume of tracts on $\mathrm{x}$-axis and 16 subjects in $\mathrm{y}$-axis to compare both left and right side of female datasets graphically. We found that on average, the left side of male is greater when compared with left -side of female subjects. 


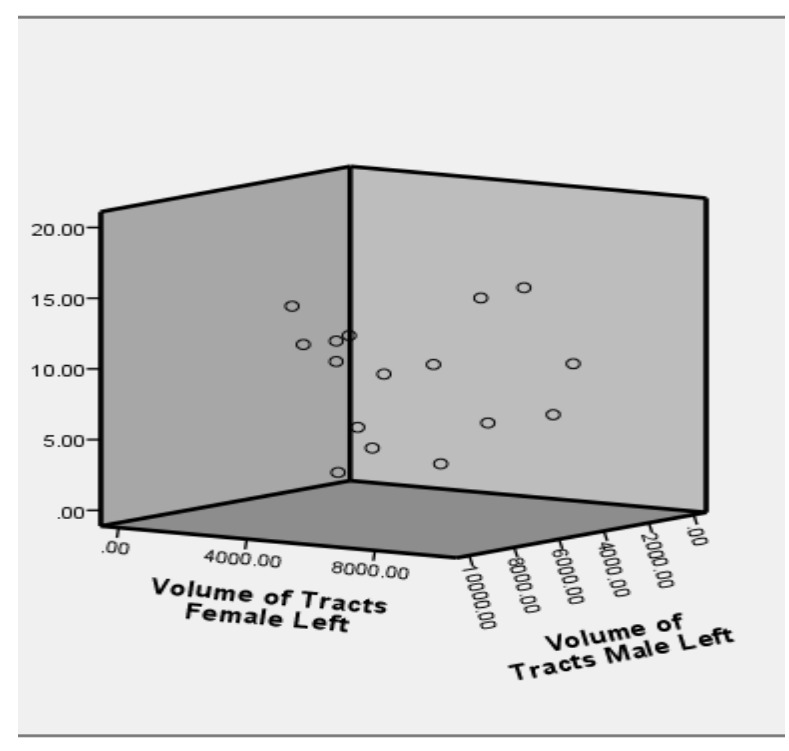

Graph-8: Comparison of Volume of Tracts in left side of female and male Ventral Stream Visual Pathway

We conclude that no complete left-side dominance of ventral stream visual pathway is seen in male and female subjects since if one side has less fibres the other side is balanced with its equalising fibres.

\section{iii) Mean Length of tracts}

Tract mean length $(\mathrm{mm})$ the average absolute deviation of a data from a central point. We are analysing tract mean length (mm) present in both the sexes (i.e. i) Male subjects and ii) Female subjects. The comparison of Mean Length of Fibres is mostly done between the seed and the end region under four parameters;

a) Male Right and Left Side

b) Female Right and Left side

c) Right side Male and Female

d) Left side Male and Female

\section{a) Right and Left side of male subjects}

The Fibres were traced and observed for neural structural connectivity on both right and left side in all sixteen healthy adult male datasets (Table-9).

Dataset numbers 1006, 1007. 1011, 1013, 1014, 1016, 102 7, 1029, 1031 shows greater number of tracts at right side. Dataset numbers 1008, 1009, 1015, 1022, 1027, 1028, 1030 shows a greater number of tracts on left side. Therefore, from the table given below, 9 datasets have 
bioRxiv preprint doi: https://doi.org/10.1101/486639; this version posted December 4, 2018. The copyright holder for this preprint (which was not certified by peer review) is the author/funder, who has granted bioRxiv a license to display the preprint in perpetuity. It is made available under ACC-BY-ND 4.0 International license.

more fibers at right and 7 datasets have more fibers at left but the variation in the mean length of fibers are more on right side (dataset number 1030).

Table 9: Mean Length of Fibres in Male Right and Left*

\begin{tabular}{|c|c|c|}
\hline Subject & $\begin{array}{c}\text { Length of Tracts } \\
\text { Mean(mm) Right }\end{array}$ & $\begin{array}{l}\text { Length of } \\
\text { Tracts Mean(mm) } \\
\text { Left }\end{array}$ \\
\hline 1006 & 112.114 & 86.2999 \\
1007 & 91.6493 & 102.975 \\
\hline 1008 & 111.561 & 97.361 \\
\hline 1009 & 95.4516 & 91.4074 \\
\hline 1011 & 94.2561 & 108.222 \\
1013 & 99.3921 & 103.787 \\
\hline 1014 & 102.589 & 119.844 \\
\hline 1015 & 94.4761 & 97.666 \\
\hline 1016 & 97.7039 & 88.922 \\
\hline 1022 & 95.6268 & 113.468 \\
\hline 1025 & 96.9707 & 122.641 \\
\hline 1027 & 99.1497 & 119.758 \\
\hline 1028 & 101.312 & 100.107 \\
\hline 1029 & 101.808 & 109.768 \\
\hline 1030 & 114.347 & 105.942 \\
\hline 1031 & 107.152 & 105.942 \\
\hline
\end{tabular}

*p-value is 600727 , result is not significant at $p<.10$

When the results were statistically compared by performing independent t-test, no significant difference was seen between the mean length of tracts in right side of male subjects.

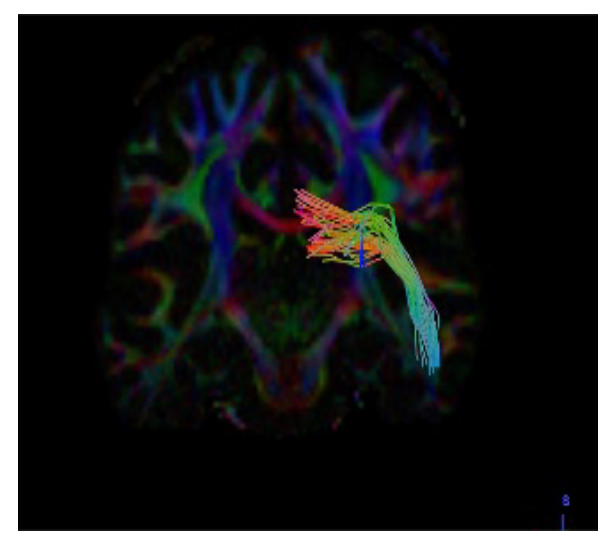

(Fig 18 ) Coronal section Dataset Subject -1030 Male right side 


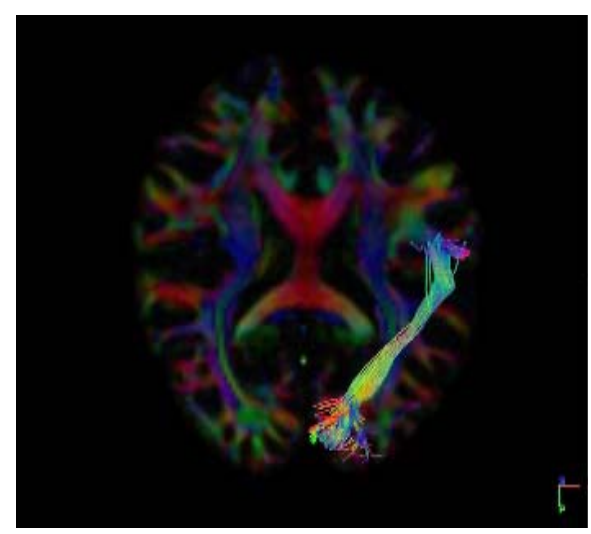

(Fig 19) Axial section Dataset Subject -1030 Male left side

\section{Graphical Representation:}

(Graph-9) plot showing Mean Length of tracts on $\mathrm{x}$-axis and 16 subjects on $\mathrm{y}$-axis to compare both left and right side of female datasets graphically. And we found that on an average right side of male is greater when compared with left -side of male subjects.

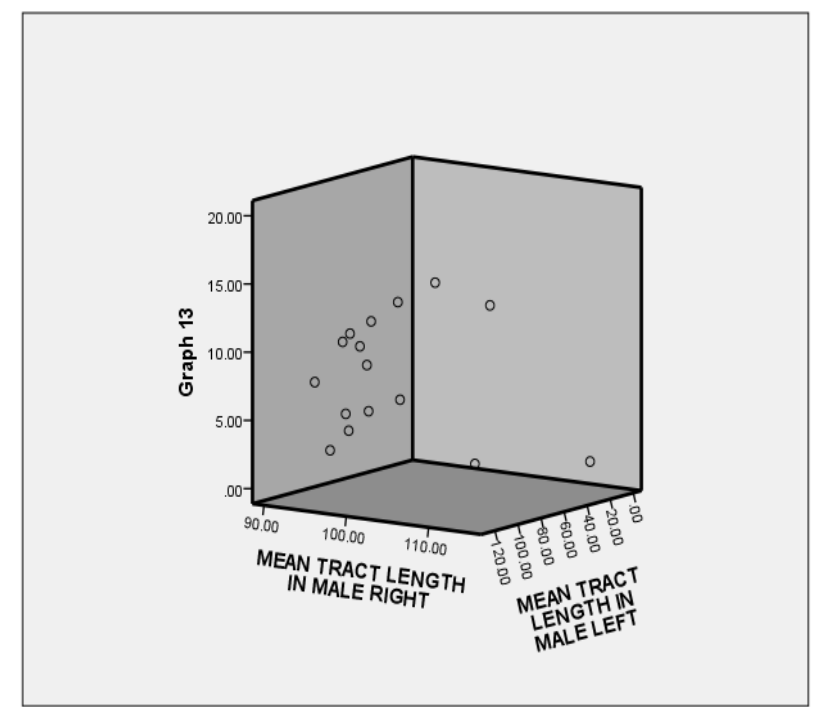

Graph-10: Comparison of Mean Length of Tracts in male right and left side

We conclude that there is no complete right-side dominance or complete left-side dominance of ventral stream visual pathway in male and female subjects, and since if one side has less fibres, the other side is balanced with its equalising fibres.

\section{b) Right and Left side of Female subjects}

The Fibres were traced and observed for neural structural connectivity on both right and left side in all sixteen healthy adult female datasets (Table10). Dataset numbers 1002, 1012, 1019, 1021, 1023, 1024, 1033 shows greater number of tracts at right side. Dataset number 1001, $1003,1004,1005,1010,1026,1035$ shows a greater Mean length of tracts on left side. Datasets 
number 1017 and 1032 does not show any great difference between the tracts. Therefore, from the table given below, 6 datasets have more fibers at right and 6 datasets have more fibers at left and no difference has been seen in 2 datasets but the variation in the mean length of fibers are more in Left Side (dataset number 1021).

Table 10: Mean Length of Tracts in Female Right and Left *

\begin{tabular}{|c|c|c|c|}
\hline Subject & $\begin{array}{l}\quad \text { Length of } \\
\text { Tracts } \\
\text { Mean }(\mathrm{mm}) \text { Right }\end{array}$ & $\begin{array}{c}\text { Length of } \\
\operatorname{Mean}(\mathrm{mm}) \text { Left }\end{array}$ & Tracts \\
\hline 1001 & 106.752 & 94.8221 & \\
\hline 1002 & 109.728 & 103.318 & \\
\hline 1003 & 95.1141 & 95.034 & \\
\hline 1004 & 100.122 & 101.919 & \\
\hline 1005 & 93.776 & 101.059 & \\
\hline 1010 & 92.1292 & 94.5857 & \\
\hline 1012 & 99.1144 & 98.1627 & \\
\hline 1017 & 105.575 & 91.3946 & \\
\hline 1019 & 105.151 & 98.9259 & \\
\hline 1021 & 111.763 & 91.7771 & \\
\hline 1023 & 107.889 & 104.036 & \\
\hline 1024 & 107.667 & 98.6967 & \\
\hline 1026 & 84.4058 & 100.648 & \\
\hline 1032 & 105.667 & 114.255 & \\
\hline 1033 & 108.95 & 104.669 & \\
\hline 1035 & 92.1292 & 111.022 & \\
\hline
\end{tabular}

When the results were statistically compared by performing independent t-test, no significant difference was seen between the number of tracts in right and left side of female subjects.

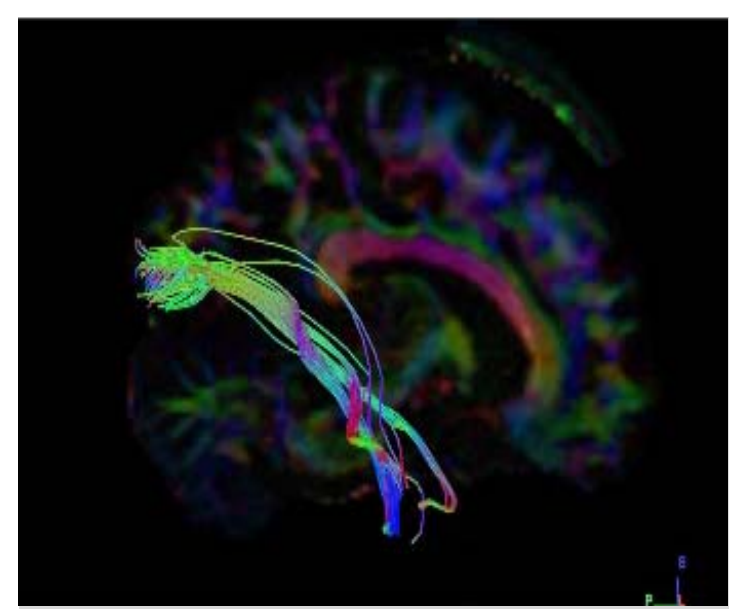

(Fig 20) Sagittal section Dataset Subject -1021 Female right side 


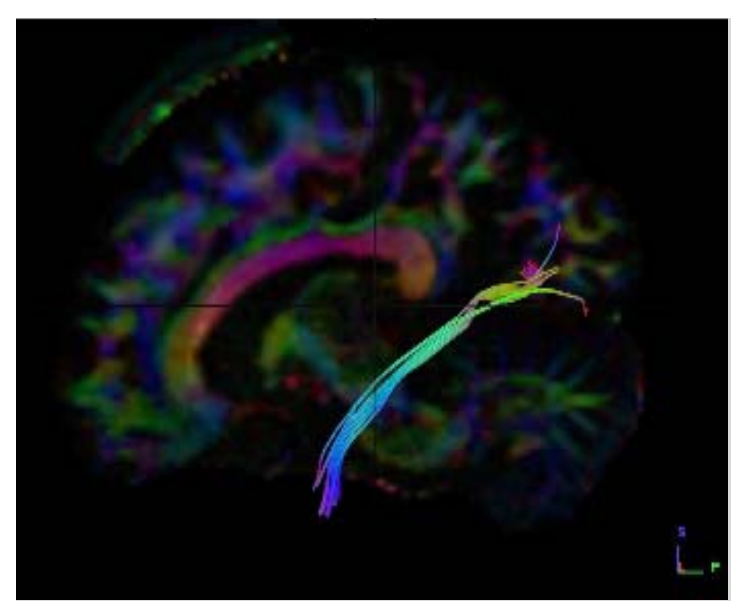

(Fig 21 ) Sagittal section Dataset Subject -1021 Female left side

\section{Graphical Representation:}

(Graph-10) plot showing Mean Length of tracts on $\mathrm{x}$-axis and 16 subjects on $\mathrm{y}$-axis to compare both left and right side of female datasets graphically. And we found that on average, left side is having a greater number of tracts when compared with right side in female subjects.

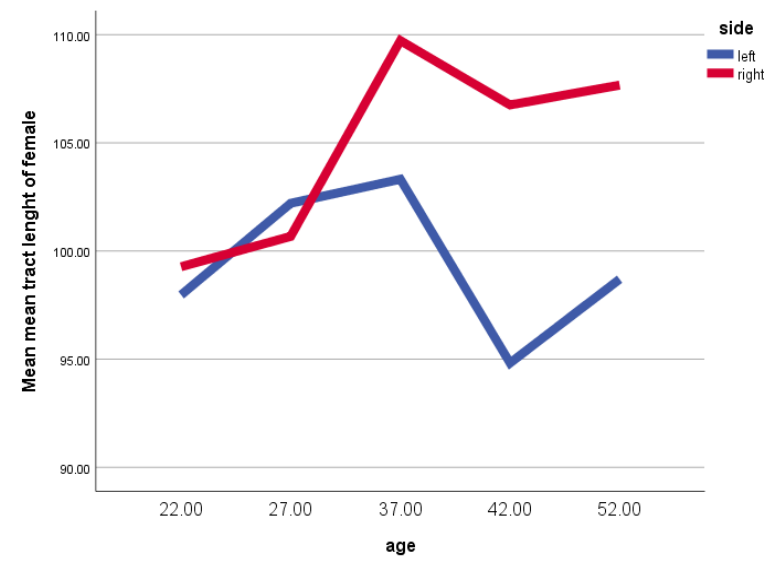

Graph-10: Comparison of Mean Length of Tracts on female right and left side

We conclude that there is no complete right side or complete left side dominance of ventral stream visual pathway in females. Hence, if one side has less fibres, the other side is balanced with its equalising fibres. Similar vice versa changes were seen if there are more fibres on one side, the other side is balanced with a smaller number of fibres.

\section{c) Right side of Female and male subjects}

The Fibres were traced and observed for neural structural connectivity on both right and left sides in all sixteen healthy adult female datasets (Table-11).

Dataset numbers 1002, 1010, 1012, 1019, 1023, 1024, 1026, 1033, 1035 show greater number of tracts on female. Dataset numbers 1006, 1007, 1008, 1011, 1013, 1025, 1027, 1029, 1031 
bioRxiv preprint doi: https://doi.org/10.1101/486639; this version posted December 4,2018 . The copyright holder for this preprint (which was not certified by peer review) is the author/funder, who has granted bioRxiv a license to display the preprint in perpetuity. It is made available under ACC-BY-ND 4.0 International license.

show a greater Mean Length of tracts in males. Therefore, from the table given below, 9 datasets have more fibers in male and 9 datasets have more fibers in female but the variation in the Mean Length of fibers are more seen in right Side of male subject (dataset number 1024).

Table 11: Mean length of fibres in Female and Male Right*

\begin{tabular}{|c|c|c|}
\hline Subject & $\begin{array}{c}\text { Length of Tracts } \\
\text { Mean(mm) Female }\end{array}$ & $\begin{array}{c}\text { Length of Tracts } \\
\text { Mean(mm) Male }\end{array}$ \\
\hline 1006 & $\mathbf{1 0 6 . 7 5 2}$ & 112.114 \\
\hline 1007 & 109.728 & 91.6493 \\
\hline 1008 & 95.1141 & 111.561 \\
\hline 1009 & 100.122 & 95.4516 \\
\hline 1011 & 93.776 & 94.2561 \\
\hline 1013 & 92.1292 & 99.3921 \\
\hline 1014 & 99.1144 & 102.589 \\
\hline 1015 & 105.575 & 94.4761 \\
\hline 1016 & 105.151 & 97.7039 \\
\hline 1022 & 111.763 & 95.6268 \\
\hline 1025 & 107.889 & 96.9707 \\
\hline 1027 & 107.667 & 99.1497 \\
\hline 1028 & 84.4058 & 101.312 \\
\hline 1029 & 105.667 & 101.808 \\
\hline 1030 & 108.95 & 114.347 \\
\hline 1031 & 92.1292 & 107.152 \\
\hline
\end{tabular}

*The $p$-value is .441763 . The result is not significant at $p<.10$.

When the results were statistically compared by performing independent t-test, no significant difference was seen between the Mean length of tracts in female and male subjects on right side.

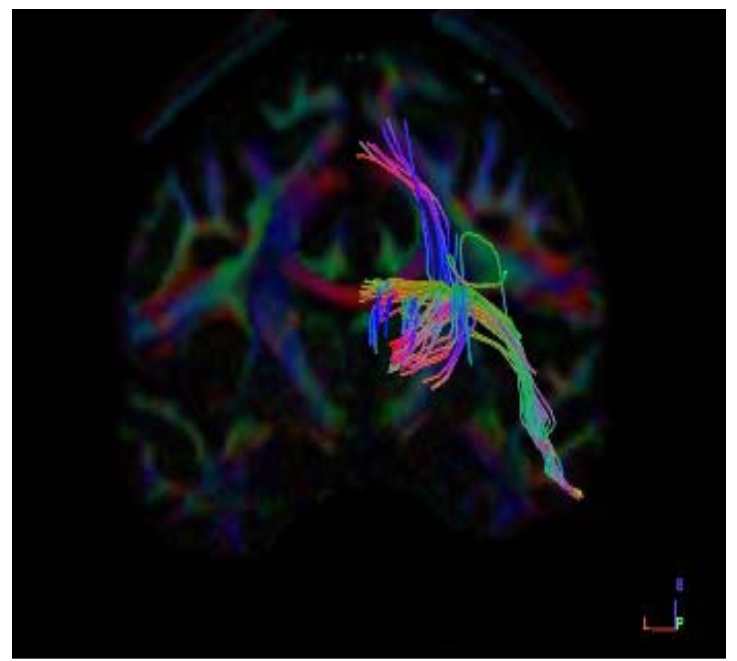

(Fig 20 ) Coronal section Dataset Subject -1024 Female right side 


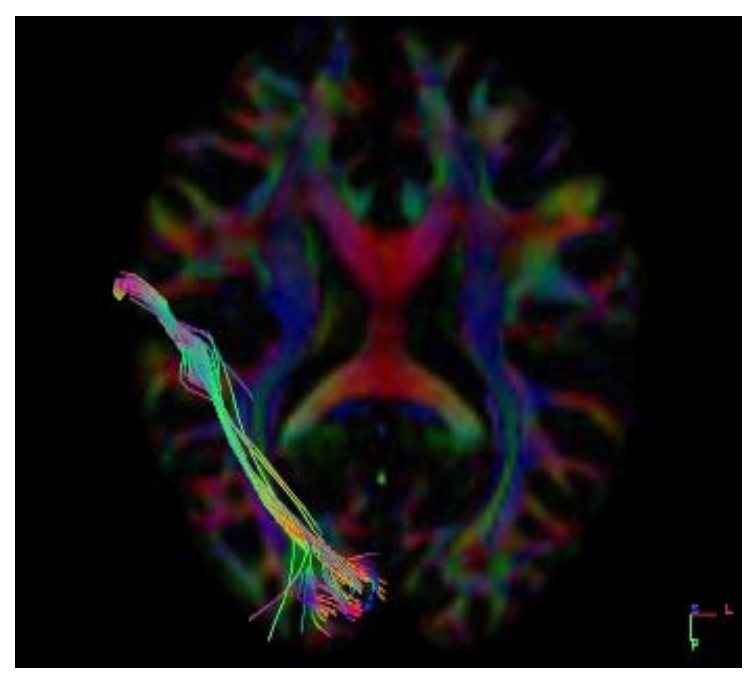

(Fig 21) Axial Section Dataset Subject -1024 male right side

\section{Graphical Representation:}

(Graph-11) plot showing Length of tracts on $\mathrm{x}$-axis and 16 subjects on $\mathrm{y}$-axis to compare both left and right side of female datasets graphically. On an average, we found that the right-side has a greater Mean Length of tracts in males when compared with right side in female subjects.

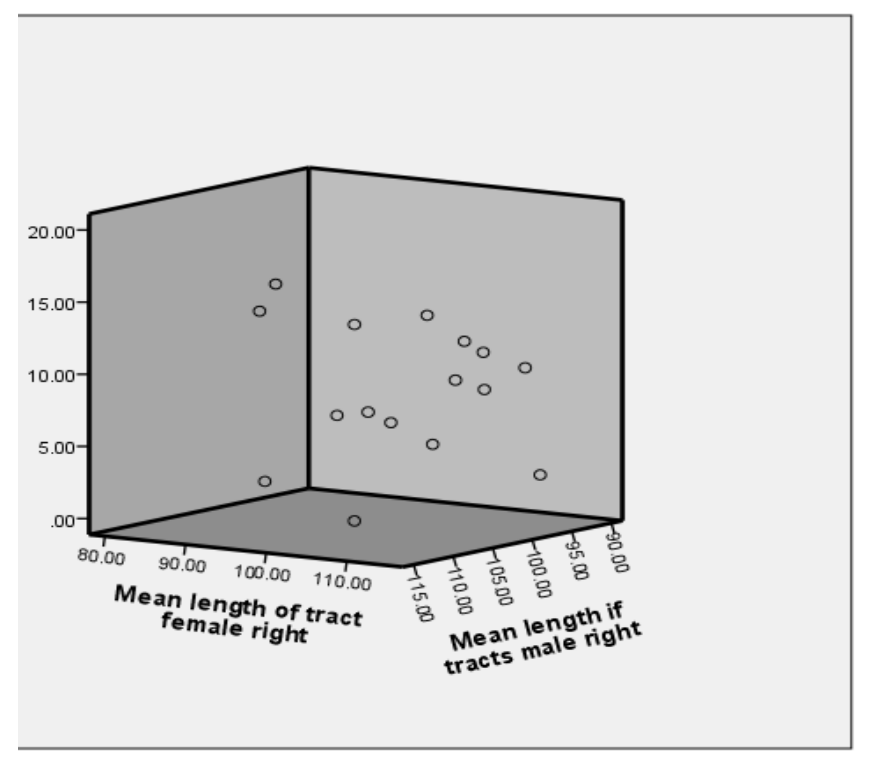

We conclude that there is no complete right-side dominance of ventral stream visual pathway in both male and female subjects.

\section{d) Left side of Male and Female subjects}

The Fibres were traced and observed for neural structural connectivity on both right and left side in all sixteen healthy adult female datasets (Table-12). 
Dataset numbers 1002, 1010, 1012, 1019, 1023, 1024, 1026, 1033, 1035 shows greater number of tracts on females. Dataset numbers 1006, 1007, 1008, 1011, 1013, 1025, 1027, 1029, 1031 shows a greater Mean Length of tracts in males. Therefore, from the table given below, 9 datasets have more fibers in male and 9 datasets have more fibers in female but the variation in the Mean Length of fibers are more seen on left side in male subject (dataset number 1024).

Table 12: Mean length of fibres in Female and Male Left **

\begin{tabular}{|c|c|c|}
\hline S.NO & $\begin{array}{ccc}\text { Length } & \text { of } & \text { Tracts } \\
\text { Mean }(\mathrm{mm}) & \text { Female }\end{array}$ & $\begin{array}{c}\text { Length of } \\
\text { Tracts } \operatorname{Mean}(\mathrm{mm})\end{array}$ \\
\hline 1 & 94.8221 & 86.2999 \\
\hline 2 & 103.318 & 102.975 \\
\hline 3 & 95.034 & 97.361 \\
\hline 4 & 101.919 & 91.4074 \\
\hline 5 & 101.059 & 108.222 \\
\hline 6 & 94.5857 & 103.787 \\
\hline 7 & 98.1627 & 119.844 \\
\hline 8 & 91.3946 & 97.666 \\
\hline 9 & 98.9259 & 88.922 \\
\hline 10 & 91.7771 & 113.468 \\
\hline 11 & 104.036 & 122.641 \\
\hline 12 & 98.6967 & 119.758 \\
\hline 13 & 100.648 & 100.107 \\
\hline 14 & 114.255 & 109.768 \\
\hline 15 & 104.669 & 105.942 \\
\hline 16 & 111.022 & 105.942 \\
\hline
\end{tabular}

*** $p$-value is .000031 , result is significant at $p<.10$

When the results were statistically compared by performing independent t-test, significant difference was seen between the Mean length of tracts in female and male subjects on left side.

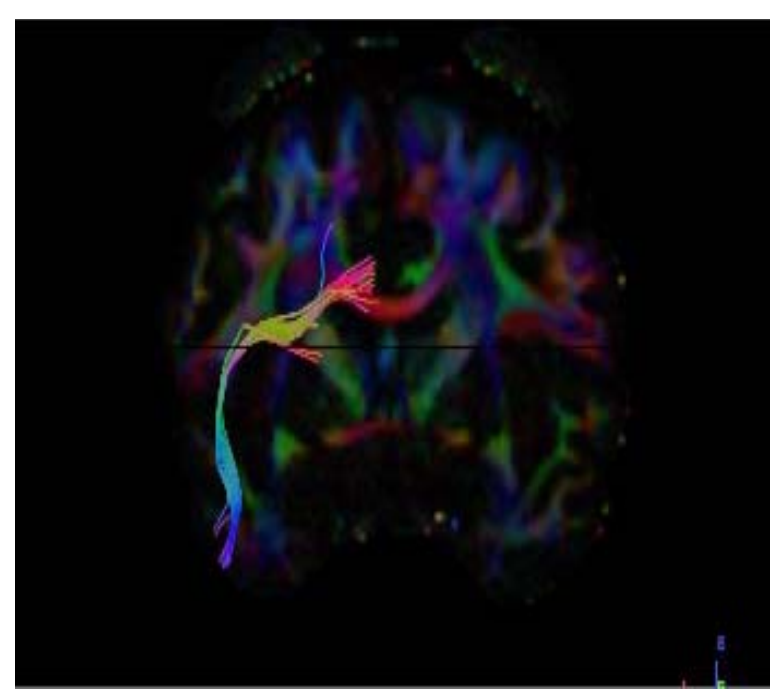

(Fig 22 ) Coronal section Dataset Subject -1024 Female left side 


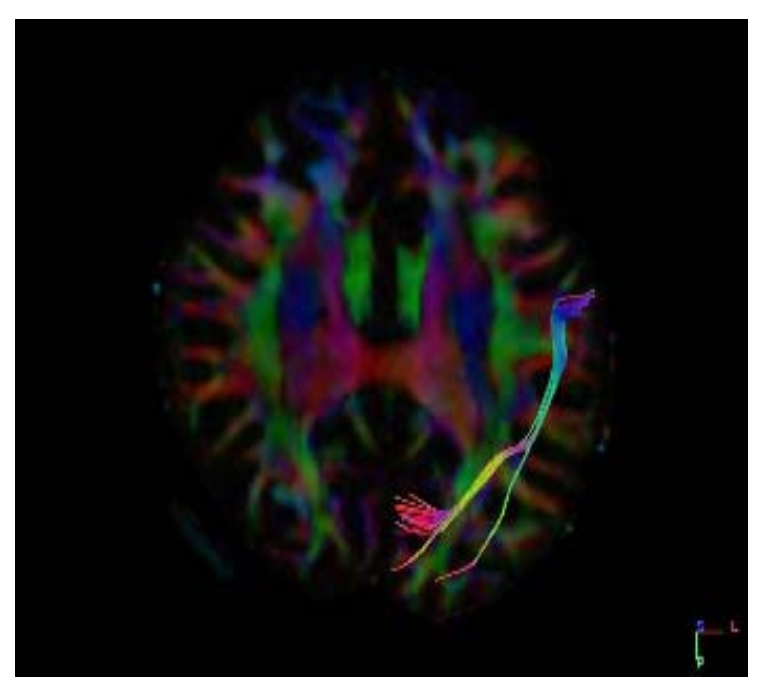

(Fig 23) Axial Section Dataset Subject - 1024 male left side

\section{Graphical Representation:}

(Graph-12) plot showing Mean Length of tracts on x-axis and 16 subjects on y-axis to compare the left of both male and female datasets graphically. On average,we found that the left-side has a greater Mean Length of tracts in males when compared with Left side in female subjects.

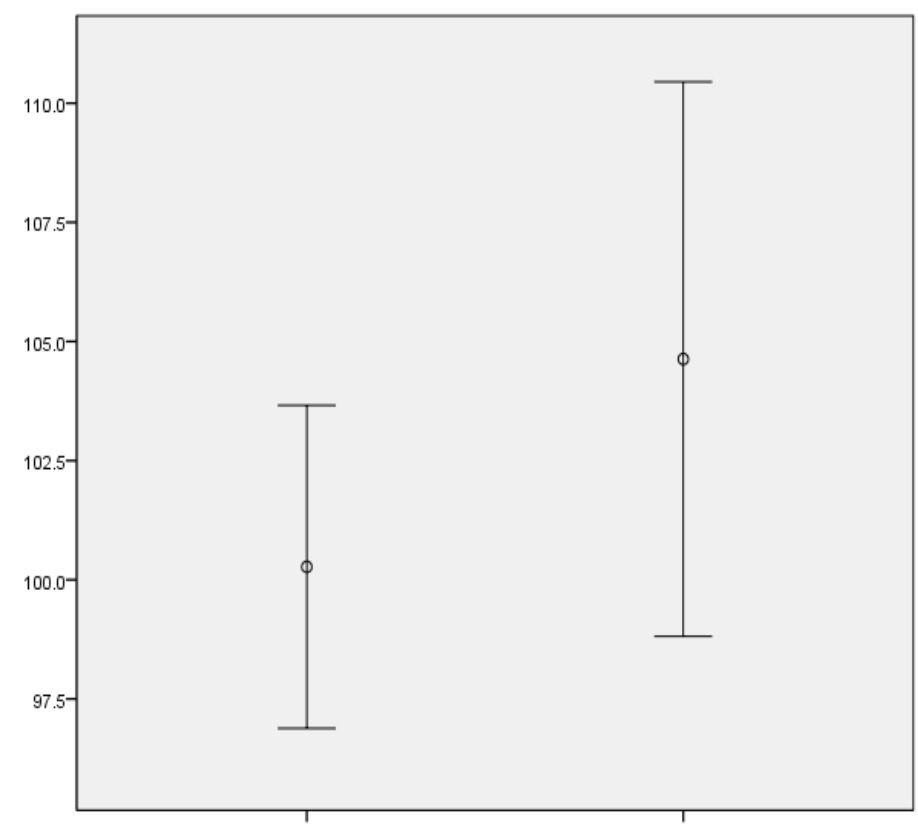

Mean length of fibres in Female at Left

Mean length of fibres in Male at Left 
We conclude that there is complete left-side dominance of ventral stream visual pathway in both males and females. Therefore when a person has left dominance of ventral stream visual pathway, they have a better ability to interpret conceptual perception of objects.

iv) Tract Length Standard Deviation

Tract length standard deviation is a measure that is used to quantify the amount of variation or dispersion of a set of data values. We are analysing tract mean length $(\mathrm{mm})$ present in both the sexes i.e.

i) Male subjects and ii) Female subjects.
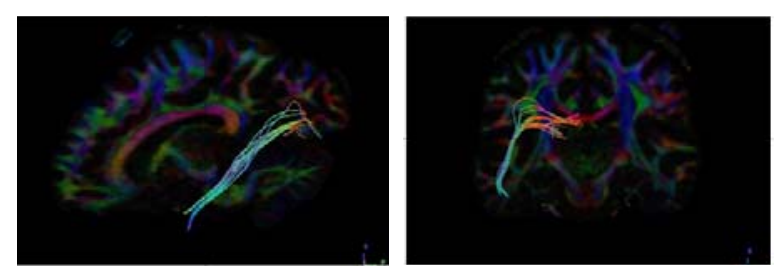

TABLE 13: TRACT LENGTH STANDARD DEVIATION IN MALE RIGHT

\begin{tabular}{|l|l|l|l|}
\hline Subject & Gender & Age & $\begin{array}{l}\text { Tracts Iength } \\
\text { Standard } \\
\left(\mathbf{m m}^{\wedge} \mathbf{3}\right)\end{array}$ \\
\hline 1 & Male & $40-44$ & $\mathbf{1 5 . 9 8 3 1}$ \\
\hline 2 & Male & $35-39$ & $\mathbf{5 . 7 1 7 7 2}$ \\
\hline 3 & Male & $25-29$ & $\mathbf{2 5 . 0 0 4}$ \\
\hline 4 & Male & $25-29$ & $\mathbf{7 . 8 7 8 8}$ \\
\hline 5 & Male & $25-29$ & $\mathbf{1 0 . 7 8 7 4}$ \\
\hline 6 & Male & $25-29$ & $\mathbf{1 1 . 8 0 6 3}$ \\
\hline 7 & Male & $20-24$ & $\mathbf{8 . 2 5 2 3 8}$ \\
\hline 8 & Male & $25-29$ & $\mathbf{1 . 8 2 4 2 6}$ \\
\hline 9 & Male & $25-29$ & $\mathbf{1 2 . 2 6 2 9}$ \\
\hline 10 & Male & $20-24$ & $\mathbf{2 . 9 5 2 9 7}$ \\
\hline 11 & Male & $25-29$ & $\mathbf{9 . 3 1 4 0 4}$ \\
\hline 12 & Male & $45-59$ & $\mathbf{1 7 . 3 4 5 3}$ \\
\hline 13 & Male & $20-24$ & $\mathbf{9 . 6 0 5 7 5}$ \\
\hline 14 & Male & $25-29$ & $\mathbf{1 1 8 1 9 . 3}$ \\
\hline 15 & Male & $20-24$ & $\mathbf{4 . 2 8 5 1 7}$ \\
\hline 16 & Male & $25-29$ & $\mathbf{1 5 . 8 1 1 5}$ \\
\hline
\end{tabular}


bioRxiv preprint doi: https://doi.org/10.1101/486639; this version posted December 4, 2018. The copyright holder for this preprint (which was not certified by peer review) is the author/funder, who has granted bioRxiv a license to display the preprint in perpetuity. It is made available under aCC-BY-ND 4.0 International license.

TABLE 16: TRACT LENGTH STANDARD DEVIATION IN MALE LEFT

\begin{tabular}{|l|l|l|l|}
\hline Subject & Gender & Age & $\begin{array}{l}\text { Tracts length } \\
\text { Standard } \\
\left(\mathbf{m m}^{\wedge} \mathbf{3}\right)\end{array}$ \\
\hline 1 & Male & $40-44$ & $\mathbf{0}$ \\
\hline 2 & Male & $35-39$ & 4.41691 \\
\hline 3 & Male & $25-29$ & $\mathbf{9 . 5 0 6 2 4}$ \\
\hline 4 & Male & $25-29$ & $\mathbf{8 . 3 1 4 4 3}$ \\
\hline 5 & Male & $25-29$ & $\mathbf{1 4 . 2 4 7 1}$ \\
\hline 6 & Male & $25-29$ & $\mathbf{1 6 . 6 7 9 9}$ \\
\hline 7 & Male & $20-24$ & $\mathbf{0}$ \\
\hline 8 & Male & $25-29$ & $\mathbf{0}$ \\
\hline 9 & Male & $25-29$ & $\mathbf{5 . 6 0 5}$ \\
\hline 10 & Male & $20-24$ & $\mathbf{1 0 . 2 8 8 6}$ \\
\hline 11 & Male & $25-29$ & $\mathbf{2 3 . 7 8 9 7}$ \\
\hline 12 & Male & $45-59$ & $\mathbf{1 2 . 5 7 9 5}$ \\
\hline 13 & Male & $20-24$ & $\mathbf{1 0 . 4 6 3 4}$ \\
\hline 14 & Male & $25-29$ & $\mathbf{1 0 . 4 3 7 8}$ \\
\hline 15 & Male & $20-24$ & $\mathbf{9 . 0 3 0 9 1}$ \\
\hline 16 & Male & $25-29$ & $\mathbf{9 . 0 3 0 9 1}$ \\
\hline & & & -1.13136 \\
\hline
\end{tabular}

$\mathrm{T}-$ Test calculation results retrieved from Table $31 \& 32$ : The $t$-value is -1.13136 . The $p$-value is .266865. The result is not significant at $p<.10$

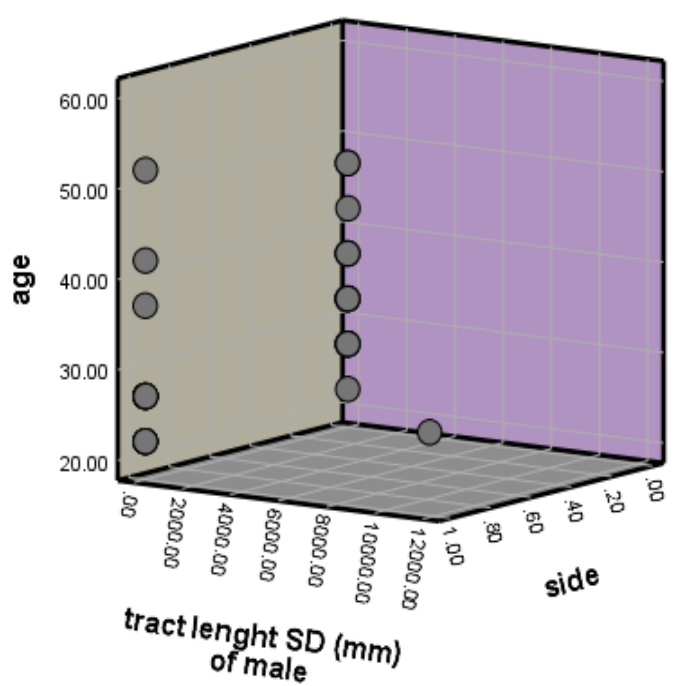

TABLE 17: TRACT LENGTH STANDARD DEVIATION IN FEMALE RIGHT

\begin{tabular}{|l|l|l|l|}
\hline Subject & Gender & Age & $\begin{array}{l}\text { Tracts length Mean } \\
\text { Standard Deviation }\end{array}$ \\
\hline
\end{tabular}




\begin{tabular}{|l|l|l|l|}
\hline & & & $\left(\mathbf{m m}^{\wedge} \mathbf{3}\right)$ \\
\hline 1 & Female & $40-44$ & $\mathbf{8 . 0 3 5 2 7}$ \\
\hline 2 & Female & $35-39$ & $\mathbf{2 1 . 6 5 4 5}$ \\
\hline 3 & Female & $25-29$ & $\mathbf{1 1 . 9 4 7 9}$ \\
\hline 4 & Female & $25-29$ & $\mathbf{7 . 2 7 0 6 4}$ \\
\hline 5 & Female & $25-29$ & $\mathbf{6 . 0 3 2 3}$ \\
\hline 6 & Female & $25-29$ & $\mathbf{1 0 . 9 6 5 9}$ \\
\hline 7 & Female & $20-24$ & $\mathbf{1 1 4 9 3 9}$ \\
\hline 8 & Female & $25-29$ & $\mathbf{8 . 0 5 7 3 5}$ \\
\hline 9 & Female & $25-29$ & $\mathbf{8 . 9 8 7 7 9}$ \\
\hline 10 & Female & $20-24$ & $\mathbf{1 5 . 4 4 2 3}$ \\
\hline 11 & Female & $25-29$ & $\mathbf{8 . 3 5 3 7}$ \\
\hline 12 & Female & $45-59$ & $\mathbf{7 . 3 0 0 4 6}$ \\
\hline 13 & Female & $20-24$ & $\mathbf{6 . 0 6 7 7 9}$ \\
\hline 14 & Female & $25-29$ & $\mathbf{1 0 . 2 7 4 7}$ \\
\hline 15 & Female & $20-24$ & $\mathbf{1 8 . 5 1 6 5}$ \\
\hline 16 & Female & $25-29$ & $\mathbf{1 0 . 9 6 5 9}$ \\
\hline
\end{tabular}

TABLE 18: TRACT LENGTH STANDARD DEVIATION IN FEMALE LEFT

\begin{tabular}{|l|l|l|l|}
\hline Subject & Gender & Age & $\begin{array}{l}\text { Tracts length Mean } \\
\text { Standard } \\
\left(\mathbf{m m}^{\wedge} 3\right)\end{array}$ \\
\hline 1 & Female & $40-44$ & $\mathbf{7 . 0 3 8 4 1}$ \\
\hline 2 & Female & $35-39$ & $\mathbf{2 . 6 5 1 8 3}$ \\
\hline 3 & Female & $25-29$ & $\mathbf{1 1 . 7 0 9 5}$ \\
\hline 4 & Female & $25-29$ & $\mathbf{4 . 0 9 3 9}$ \\
\hline 5 & Female & $25-29$ & $\mathbf{1 6 . 7 2 6 9}$ \\
\hline 6 & Female & $25-29$ & $\mathbf{7 . 9 7 7 1 4}$ \\
\hline 7 & Female & $20-24$ & $\mathbf{8 . 3 1 9 9 9}$ \\
\hline 8 & Female & $25-29$ & $\mathbf{5 . 7 5 6 3 2}$ \\
\hline 9 & Female & $25-29$ & $\mathbf{8 . 8 6 8 8 8}$ \\
\hline 10 & Female & $20-24$ & $\mathbf{6 . 3 3 2 3 3}$ \\
\hline 11 & Female & $25-29$ & $\mathbf{1 2 . 3 9 2 5}$ \\
\hline 12 & Female & $45-59$ & $\mathbf{1 2 . 2 7 8 7}$ \\
\hline 13 & Female & $20-24$ & $\mathbf{1 2 . 3 4 1 6}$ \\
\hline 14 & Female & $25-29$ & $\mathbf{8 . 7 3 7 0 4}$ \\
\hline 15 & Female & $20-24$ & $\mathbf{8 . 9 1 8 9 3}$ \\
\hline 16 & Female & $25-29$ & $\mathbf{1 3 . 1 3 2 3}$ \\
\hline
\end{tabular}

$\mathrm{T}$ - Test calculation results retrieved from Table 23\& 24:: The $t$-value is 1.0002 . The $p$-value is .325212 . The result is not significant at $p<.10$. 


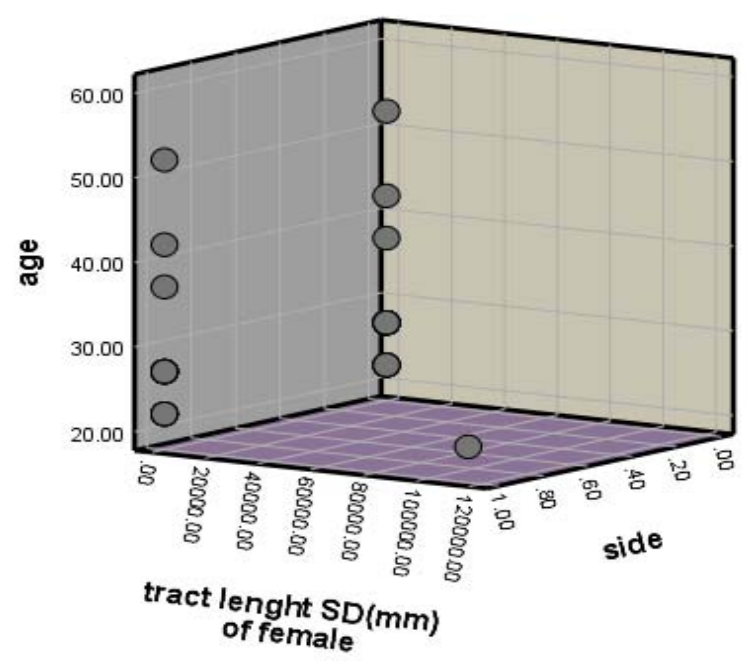

\section{Discussion and Conclusion:}

According to previous records and publications, there are many well-known scientists who have spent their lives to study the mechanism of dorsal and ventral stream of the vision. The great finding of two separate mechanisms of visual systems in monkey was stated by Treva in 1968 (1). This formed a path for the establishment and identification of dorsal and ventral stream. In 1969, Schneider stated the two visual pathways for locating and identifying objects (2). Later, Ingle in 1973 visualized the two systems in frogs (3). After 9 years, i.e. in 1992, Ungerleider and Mishkin were able to differentiate the dorsal and ventral streams with respect to processing spatial and visual features, based on studies and research done on monkeys (4). But it wasn't a long success as it was superseded by Milner \&amp; Goodale in later years. The existence of functional differences in the dorsal and ventral streams were stated by Huxby in 1994 by proposing the "What" and "Where" as two different pathways through positron emission tomography (5). In 2002, Norman stated the two theories of perception, where the ventral streams' central function is identification of objects (6). Polanen and Davere in 2015 stated that there is an interaction between the dorsal and ventral streams where the dorsal is fed by the ventral. They also proposed that there is a direct white matter connection between dorsal and ventral which helps them to interact each other bidirectionally. Hence, scientists previously haven't given any proof of structural connection, however, we are postulating a new concept of structural connection where the connectivity of the ventral stream has been stated. In this article, we have proposed that the ventral stream visual pathway has a neuronal 
structural connectivity where a group of fibres in the central nervous system forms tracts that pass from the primary visual cortex to the inferior temporal lobe and enables individuals to perceive objects. Additionally, the fibres that interconnects Brodmann area 17,18,19 to Brodmann area 20 allows for flow the visual information for the perception of an object thus, forming an occipitotemporal network. This interesting connection forming a true occipitotemporal network is what helps a person perceive an object, its shape, colour and also the different characteristics of the object.

Hence, during our study, we analyzed a list of parameters inclusive of number of tracts, tract length, its volume and standard deviation of the tract length which could be useful in recognizing the cause for different neurodegenerative disorders. Typical long-term memory and the ability to organize an object spatially are the most important function of ventral stream visual pathway. While the dorsal helps the ventral stream to interpret the object by sending the spatial information of dorsal to the ventral stream. But the major question is how both the dorsal and ventral streams coordinate structurally with each other to provide a pure output of information about the object location. Analysis from our study shows that females and males predominately possess similar number of fibres passing from the primary visual cortex to the inferior temporal lobe. When it comes to the tract volume and tract mean standard deviation (SD) of the fibres, there was a vast difference seen with females having more volume and SD than the males. The tract length of the fibres in both male and female showed similar result.. Hence, we conclude by stating that the there is an existence of a structural connection enabling the transfer of information. Polanen mentioned that bilateral damage to the inferior temporal lobe leads to damage to the ventral stream visual pathway and and this deprived some patients of the ability of object perception, hence, any damage to the ventral stream may lead the patients developing apperceptive visual agnosia. Apperceptive form of visual agnosia is where patients suffer lack of coordination and they do not usually recognize objects and hence cannot grasp objects thus, this shows there is a lack of interaction of the ventral stream with the dorsal stream.

\section{References}

[1] Wright, M. J. (1969). Visual Receptive Fields of Cells in a Cortical Area remote from the Striate Cortex in the Cat. Nature, 223(5209), 973-975. doi:10.1038/223973a0. Retrieved; 12/05/2018.

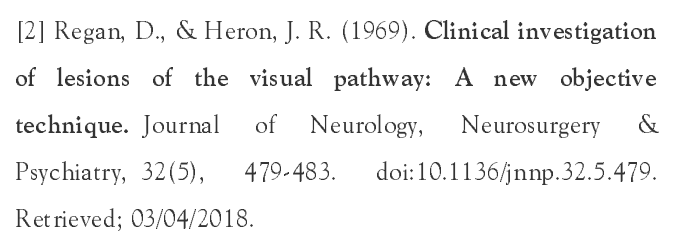

[3] Allman, J. M., \& Kaas, J. H. (1971). Representation of the visual field in striate and adjoining cortex of the owl 
monkey (Aotus trivirgatus). Brain Research, 35(1), 89-106. doi:10.1016/0006-8993(71)90596-8. Retrieved; 09/05/2018.

[4] Haaxma, R., \& Kuypers, H. G. (1975). Intrahemispheric Cortical Connexions And Visual Guidance Of Hand And Finger Movements In The Rhesus Monkey. Brain, 98(2), 239-260. doi:10.1093/brain/98.2.239. Retrieved; 23/03/2018.

[5] Seltzer, B., \& Pandya, D. N. (1978). Afferent cortical connections and architectonics of the superior temporal sulcus and surrounding cortex in the rhesus monkey. Brain Research, 149(1), 1-24. doi:10.1016/0006-8993(78)90584-x. Retrieved; 07/05/2018.

[6] Leinonen, L., HyvRinen, J., Nyman, G., \& Linnankoski, I. (1979). I. Functional properties of neurons in lateral part of associative area 7 in awake monkeys. Experimental Brain Research,34(2). doi: 10.1007/bf00235675. Retrieved; 30/01/2018.

[7] Baker, J. F., Petersen, S. E., Newsome, W. T., \& Allman, J. M. (1981). Visual response properties of neurons in four extrastriate visual areas of the owl monkey (Aotus trivirgatus): A quantitative comparison of medial, dorsomedial, dorsolateral, and middle temporal areas. Journal of Neurophysiology, 45(3), 397-416. doi:10.1152/jn. 1981.45.3.397. Retrieved; 12/06/2018.

[8] Freiwald, W. (2013). Faculty of 1000 evaluation for Visual properties of neurons in a polysensory area in superior temporal sulcus of the macaque. F1000 Post-publication Peer Review of the Biomedical Literature. doi:10.3410/f.717989827.793472996. Retrieved; 14/04/2018.

[9] Andersen, R., \& Mountcastle, V. (1983). The influence of the angle of gaze upon the excitability of the lightsensitive neurons of the posterior parietal cortex. The Journal of Neuroscience, 3(3), 532-548. doi:10.1523/jneurosci.03-03-00532.1983. Retrieved; $12 / 05 / 2018$.

[10] Maunsell, J. H., \& Essen, D. C. (1983). Functional properties of neurons in middle temporal visual area of the macaque monkey. I. Selectivity for stimulus direction, speed, and orientation. Journal of Neurophysiology, 49(5), 1127-1147. doi:10.1152/jn.1983.49.5.1127. Retrieved; 09/05/2018.
[11] Mishkin, M., Ungerleider, L. G., \& Macko, K. A. (1983).

Object vision and spatial vision: Two cortical pathways. Trends in Neurosciences, 6, 414-417. doi: 10.1016/0166-2236(83)90190-x. Retrieved; 04/04/2018.

[12] Leonard, C., Rolls, E., Wilson, F., \& Baylis, G. (1985). Neurons in the amygdala of the monkey with responses selective for faces. Behavioural Brain Research, 15(2), 159-176. doi: 10.1016/0166-4328(85)90062-2. Retrieved; 06/05/2018.

[13] Moran, J., \& Desimone, R. (1985). Selective attention gates visual processing in the extrastriate cortex. Science, 229(4715), 782-784. doi: 10.1126/science.4023713. Retrieved; 10/06/2018.

[14] Motter, B., Steinmetz, M., Duffy, C., \& Mountcastle, V. (1987). Functional properties of parietal visual neurons: Mechanisms of directionality along a single axis. The Journal of Neuroscience, 7(1), 154-176. doi: 10.1523/jneurosci.07-01-00154.1987. Retrieved; 09/07/2018.

[15] Abrams, R. A., \& Landgraf, J. Z. (1990). Differential use of distance and location information for spatial localization. Perception \& Psychophysics, 47(4), 349-359. doi: 10.3758/bf03210875. Retrieved; 04/04/2018.

[16] Taira, M., Mine, S., Georgopoulos, A., Murata, A., \& Sakata, H. (1990). Parietal cortex neurons of the monkey related to the visual guidance of hand movement. Experimental Brain Research, 83(1). doi: 10.1007/bf00232190. Retrieved; 09/07/2018.

[17] Mowry, C., Pimentel, A., Sparks, E., \& Hanlon, B. (2013). Materials characterization activities for "Take Our Sons\&Daughters to Work Day” 2013. doi:10.2172/1096449. Retrieved; 10/06/2018.

[18] Haxby, J. V., Grady, C. L., Horwitz, B., Salerno, J., Ungerleider, L. G., Mishkin, M., \& Schapiro, M. B. (1993). Dissociation of Object and Spatial Visual Processing Pathways in Human Extrastriate Cortex. Functional Organisation of the Human Visual Cortex, 329-340. doi: 10.1016/b978-0-08-042004-2.50028-9. Retrieved; 02/06/2018. 
[19] Goodale, M. A., \& Milner, A. (1992). Separate visual pathways for perception and action. Trends in Neurosciences, 15(1), $20-25$. doi:10.1016/0166-2236(92)90344-8. Retrieved; 03/07/2018.

[20] Mcintosh, A., Grady, C., Ungerleider, L., Haxby, J., Rapoport, S., \& Horwitz, B. (1994). Network analysis of cortical visual pathways mapped with PET. The Journal of Neuroscience, 14(2), 655-666. doi:10.1523/jneurosci.14-02-00655.1994. Retrieved; 02/06/2018.

[21] Faillenot, I. (1997). Visual pathways for object-oriented action and object recognition: Functional anatomy with PET. Cerebral Cortex, 7(1), 77-85. doi:10.1093/cercor/7.1.77. Retrieved; 03/06/2018.

[22] Deubel, H., Schneider, W. X., \&amp; Paprotta, I. (1998). Selective Dorsal and Ventral Processing: Evidencfor a Common Attentional Mechanism in Reaching and Perception. Visual Cognition,5(1-2), 81-107. doi:10.1080/713756776. Retrieved; 03/05/2018.

[23] Desimone, R. (1998). Visual attention mediated by biased competition in extrastriate visual

cortex. Philosophical Transactions of the Royal Society B: Biological Sciences, 353(1373), 1245-1255.

doi:10.1098/rstb.1998.0280. Retrieved; 09/05/2018.

[24] Grill-Spector, K., Kushnir, T., Edelman, S., Itzchak, Y., Samp; Malach, R. (1998). Cue-Invariant Activation in

Object-Related Areas of the Human Occipital Lobe. Neuron,21(1), 191-202. doi:10.1016/s0896-6273(00)80526-7. Retrieved; 05/05/2018.

[25] Haxby, J. V. (1999). Distributed representation of objects in the human ventral visual pathway. Proceedings of the National Academy of

Sciences,96(16), 9379-9384. doi:10.1073/pnas.96.16.9379. Retrieved; 04/04/2018.

[26] Sabine Kastner And Leslie G. Ungerleider. (2000). Mechanisms of Visual Attention in the Human Cortex. Annual Review of Neuroscience,23(1), 315-341. doi:10.1146/annurev.neuro.23.1.315. Retrieved; 09/07/2018.

[27] Glickstein, M. (2000). How are visual areas of the brain connected to motor areas for the sensoryguidance of movement? Trends in Neurosciences,23(12), 613-617. doi:10.1016/s0166-2236(00)01681-7. Retrieved; 10/06/2018.

[28] Pisella, L., Gréa, H., Tilikete, C., Vighetto, A., Desmurget, M., Rode, G., Rossetti, Y. (2000). An'automatic pilot' for the hand in human posterior parietal cortex: Toward reinterpreting optic ataxia. Nature Neuroscience,3(7), 729-736. doi:10.1038/76694. Retrieved; $11 / 04 / 2018$.

[29] Amedi, A., Malach, R., Hendler, T., Peled, S., \&amp; Zohary, E. (2001). Visuo-haptic object-related activation in the ventral visual pathway. Nature Neuroscience,4(3), 324-330. doi:10.1038/85201. Retrieved; 03/07/2018.

[30] Conway, B. R. (2001). Spatial Structure of Cone Inputs to Colour Cells in Alert Macaque Primary Visual Cortex (V-1). The Journal of Neuroscience,21(8), 2768-2783. doi:10.1523/jneurosci.21-08-02768.2001. Retrieved; 09/07/2018

[31] Sigala, N., \&amp; Logothetis, N. K. (2002). Visual categorization shapes feature selectivity in the primate temporal cortex. Nature,415(6869), 318-320. doi: 10.1038/415318a. Retrieved; 06/05/2018.

[32] Hamed, S. B. (2002). Visual Receptive Field Modulation in the Lateral Intraparietal Area during Attentive Fixation and Free Gaze. Cerebral Cortex,12(3), 234-245. doi:10.1093/cercor/12.3.234. Retrieved; 08/07/2018.

[33] James, T. W., Humphrey, G., Gati, J. S., Menon, R. S., \&amp; Goodale, M. A. (2002). Differential Effects of Viewpoint on Object-Driven Activation in Dorsal and Ventral Streams. Neuron,35(4), 793-801. doi: 10.1016/s0896-6273(02)00803-6. Retrieved; 15/05/2018.

[34] Krauzlis, R. J., \&amp; Carello, C. D. (2003). Going for the goal. Nature Neuroscience,6(4), 332-333.

doi:10.1038/nn0403-332. Retrieved; 04/07/2018.

[35] Zhong, Y. (2003). Inferior Parietal Lobule Projections to Anterior Inferotemporal Cortex (Area TE) in Macaque Monkey. Cerebral Cortex,13(5), 527-540. doi:10.1093/cercor/13.5.527. Retrieved; 08/07/2018. 
[36] Tootell, R. B., Tsao, D., \&amp; Vanduffel, W. (2003). Neuroimaging Weighs In: Humans Meet Macaques in "Primate" Visual Cortex. The Journal of Neuroscience, 23(10), 3981-3989.

doi:10.1523/jneurosci.23-10-

03981.2003. Retrieved; 03/06/2018.

[37] Rizzolatti, G., \&amp; Matelli, M. (2003). Two different streams form the dorsal visual system: Anatomy and functions. Experimental Brain Research,153(2), 146-157. doi:10.1007/s00221-003-1588-0. Retrieved; 24/06/2018.

[38] Chatterjee, S., \&amp; Callaway, E. M. (2003). Parallel colour-opponent pathways to primary visual cortex. Nature,426(6967), 668-671. doi:10.1038/nature02167. Retrieved; 30/06/2018.

[39] Milner, A., \&amp; Goodale, M. (2008). Two visual systems re-viewed. Neuropsychologia,46(3),774-785 doi:10.1016/j.neuropsychologia.2007.10.005. Retrieved; $15 / 05 / 2018$.

[40] Claeys, K. G. (2004). Color Discrimination Involves Ventral and Dorsal Stream Visual Areas. Cerebral Cortex,14(7), 803-822. doi:10.1093/cercor/bhh040. Retrieved; 08/05/2018.

[41] Valyear, K. F., Culham, J. C., Sharif, N., Westwood, D., Samp; Goodale, M. A. (2006). A double dissociation between sensitivity to changes in object identity and object orientation in the ventral and dorsal visual

streams: A human fMRI study. Neuropsychologia,44(2), 218-228. doi:10.1016/j. neuropsychologia.2005.05.004 Retrieved; 07/05/2018.

[42] Ungerleider, L., \&amp; Pessoa, L. (2008). What and where pathways. Scholarpedia, 3(11), 5342.

doi:10.4249/scholarpedia.5342. Retrieved; 12/05/2018

[43] Bassi, L., Ricci, D., Volzone, A., Allsop, J. M., Srinivasan, L., Pai, A., ... Counsell, S. J. (2008). Probabilistic diffusion tractography of the optic radiations and visual function in preterm infants at term equivalent age. Brain, 131(2), 573-582. doi:10.1093/brain/awm327. Retrieved; 22/06/2018.

[44] Cohen, L., Dehaene, S., Vinckier, F., Jobert, A., \&amp; Montavont, A. (2008). Reading normal and degraded words: Contribution of the dorsal and ventral visual pathways. NeuroImage, 40(1), 353-366. doi:10.1016/j. neuroimage.2007.11.036. Retrieved; $30 / 05 / 2018$.

[45] Lichtensteiger, J., Loenneker, T., Bucher, K., Martin, E., \&amp; Klaver, P. (2008). Role of dorsal and ventral stream development in biological motion perception. NeuroReport, 19(18), 1763-1767.

doi: 10.1097/wnr.0b013e328318ede3. Retrieved; 06/05/2018.

[46] Sherbondy, A. J., Dougherty, R. F., Napel, S., \&amp; Wandell, B. A. (2008). Identifying the human optic radiation using diffusion imaging and fiber tractography. Journal of Vision, 8(10), 12-12. doi: 10.1167/8.10.12. Retrieved; 06/06/2018.

[47] Yogarajah, M., Focke, N. K., Bonelli, S., Cercignani, M., Acheson, J., Parker, G. J., . . Duncan, J. S.(2009). Defining Meyers loop-temporal lobe resections, visual field deficits and diffusion tensor tractography. Brain, 132(6),1656-1668. doi:10.1093/brain/awp114. Retrieved; 05/05/2018.

[48] Chen, C., Huang, F., Shao, H., Jin, J., Li, Z., \&amp; Zhang, C. (2009). Sectional Anatomy of the Optic Pathways on the Coronal Plane. Journal of the Chinese Medical Association, 72(10), 515-520. doi: 10.1016/s1726-4901(09) 70420-4

Retrieved; 09/07/2018.

[49] Zanon, M., Busan, P., Monti, F., Pizzolato, G., \&amp; Battaglini, P. P. (2009). Cortical ConnectionsBetween Dorsal and Ventral Visual Streams in Humans: Evidence by TMS/EEG Co-Registration. Brain Topography, 22(4), 307-317. doi:10.1007/s10548-009-0103-8. Retrieved; 04/04/2018

[50] Bridgeman, B., A. H. C. Van Der Heijden, \&amp; Velichkovsky, B. M. (1994). A theory of visual stability across saccadic eye movements. Behavioral and Brain Sciences, 17(02), 247. doi: 10.1017/s0140525x00034361. Retrieved; 09/07/2018.

[51] Fernandez-Miranda, J. C., Pathak, S., Engh, J., Jarbo, K., Verstynen, T., Yeh, F., . . Friedlander, R.(2012). High-Definition Fiber Tractography of the Human 
Brain. Neurosurgery, 71(2),

$430-453$. doi:10.1227/neu.0b013e3182592faa. Retrieved; 11/05/2018.

[52] Wang, Q., Sporns, O., \&amp; Burkhalter, A. (2012). Network Analysis of Corticocortical ConnectionsReveals Ventral and Dorsal Processing Streams in Mouse Visual Cortex. Journal of Neuroscience,32(13), 4386-4399. doi:10.1523/jneurosci.6063-11.2012. Retrieved; 04/05/2018.

[53] Becker-Bense, S., Buchholz, H., Eulenburg, P. Z., Best, C., Bartenstein, P., Schreckenberger, M., \&amp; Dieterich, M. (2012). Ventral and dorsal streams processing visual motion perception (FDG-PET study). BMC Neuroscience, 13(1), 81. doi:10.1186/1471-2202-13-81. Retrieved; 09/07/2018

[54] Vesia, M., \&amp; Crawford, J. D. (2012). Specialization of reach function in human posterior parietal cortex. Experimental Brain Research, 221(1), 1-18. doi:10.1007/s00221-012-3158-9. Retrieved; 04/05/2018.

[55] Filippi, C. G., \&amp; Cauley, K. A. (2012). Magnetic Resonance Diffusion Tensor Imaging and Diffusion Tensor Tractography in the Evaluation of Congenital and Acquired Diseases of the Pediatric Visual System. Current Pediatric Reviews, 8(3), 232-236. doi:10.2174/157339612802139406. Retrieved; 10/05/2018.

[56] Tanaka, S., Moon, C., Fukuda, M., \&amp; Kim, S. (2011). Three-dimensional visual feature representation in the primary visual cortex. NeuralNetworks, 24(10), 1022-1035.doi: 10.1016/j.n eunet.2011.05.005. Retrieved; 03/04/2018.

[57] Dicarlo, J., Zoccolan, D., \&amp; Rust, N. (2012). How Does the Brain Solve Visual Object Recognition? Neuron, 73(3), 415-434. doi:10.1016/j. neuron.2012.01.010. Retrieved; 06/05/2018.

[58] Wu, W., Rigolo, L., O $\square$ donnell, L. J., Norton, I., Shriver, S., \&amp; Golby, A. J. (2012). Visual Pathway Study Using In Vivo Diffusion Tensor Imaging Tractography to Complement

Classic

Anatomy. OperativeNeurosurgery, 70.

doi:10.1227/neu.0b013e31822 efcae. Retrieved; 08/06/2018.
[59] Cloutman, L. L. (2013). Interaction between dorsal and ventral processing streams: Where, when and how? Brain and Language, 127(2), 251-263. doi:10.1016/j. bandl.2012.08.003. Retrieved; 09/07/2018.

[60] Wärntges, S., \&amp; Michelson, G. (2014). Detailed Illustration of the Visual Field Representation along the Visual Pathway to the Primary Visual Cortex: A Graphical Summary. Ophthalmic Research,51(1), 37-41. doi:10.1159/000355464. Retrieved; 08/07/2018.

[61] Ackman, J. B., \&amp; Crair, M. C. (2014). Role of emergent neural activity in visual map development. Current Opinion in Neurobiology, 24, 166-175. doi:10.1016/j.conb.2013.11.011. Retrieved; $11 / 05 / 2018$

[62] Gervai, P. D., Sboto-Frankenstein, U. N., Bolster, R. B., Thind, S., Gruwel, M. L., Smith, S. D., \&amp; Tomanek, B. (2014). Tractography of Meyers Loop asymmetries. Epilepsy Research, 108(5), 872-882. doi:10.1016/j.eplepsyres.2014.03.006. Retrieved; 06/06/2018.

[63] Kamali, A., Hasan, K. M., Adapa, P., Razmandi, A., Keser, Z., Lincoln, J., \&amp; Kramer, L. A. (2014). Distinguishing and quantification of the human visual pathways using high-spatial-resolution diffusion tensor tractography. Magnetic Resonance Imaging, 32(7), 796-803.doi:10.1016/j.mri.2014.04.002. Retrieved; 08/05/2018

[64] Hana, A., Husch, A., Gunness, V. R., Berthold, C., Hana, A., Dooms, G., Hertel, F. (2014). DTI of the Visual Pathway - White Matter Tracts and Cerebral Lesions. Journal of Visualized Experiments, $(90)$. doi: 10.3791/51946. Retrieved; 08/07/2018.

[65] Thomas, C., Ye, F. Q., Irfanoglu, M. O., Modi, P., Saleem, K. S., Leopold, D. A., \&amp; Pierpaoli, C.(2014). Anatomical accuracy of brain connections derived from diffusion MRI tractography is inherently limited. Proceedings of the National Academy of Sciences, 111(46),

16574-16579.doi:10.1073/pnas.1405672111. Retrieved; 04/05/2018 
[66]) Gilaie-Dotan, S. (2014). Ventral \&quot;form\&quot; visual pathway and the EBA are not critical for biological motion perception: Evidence from patients and a model suggestion. Journal of Vision, 14(10), 1327- 1327. doi:10.1167/14.10.1327. Retrieved; 05/05/2018.

[67] Lim, J. C., Phal, P. M., Desmond, P. M., Nichols, A. D., Kokkinos, C., Danesh-Meyer, H. V., Moffat, B. A. (2015). Probabilistic MRI Tractography of the Optic Radiation Using Constrained Spherical Deconvolution: A Feasibility Study. Plos One, 10(3). doi:10.1371/journal.pone.0118948. Retrieved; 10/05/2018.

[68] Takemura, H., Rokem, A., Winawer, J., Yeatman, J. D., Wandell, B. A., \&amp; Pestilli, F. (2015). A Major Human White Matter Pathway Between Dorsal and Ventral Visual Cortex. Cerebral Cortex, 26(5), 2205-2214. doi:10.1093/cercor/bhv064. Retrieved; 08/05/2018.

[69] Polanen, V. V., \&amp; Davare, M. (2015). Interactions between dorsal and ventral streams for controlling skilled grasp. Neuropsychologia, 79,

186-191.doi: 10.1016/j. neuropsychologia.2015.07.010.

Retrieved; 15/05/2018.

[70] Silson, E. H., Chan, A. W., Reynolds, R. C., Kravitz, D. J., \&amp; Baker, C. I. (2015). A Retinotopic Basis for the Division of High-Level Scene Processing between Lateral and Ventral Human Occipitotemporal Cortex. Journal of Neuroscience, 35(34),

11921-11935.doi: 10.1523/jneurosci.0137-15.2015. Retrieved; 25/06/2018.

[71] Kamali, A., Hasan, K. M., Adapa, P., Razmandi, A., Keser, Z., Lincoln, J., \&amp; Kramer, L.A. (2014). Distinguishing and quantification of the human visual pathways using high-spatial-resolution diffusion tensor tractography. Magnetic Resonance Imaging, 32(7), 796-803. doi:10.1016/j.mri.2014.04.002. Retrieved; 07/05/2018.

[72] Foley, R. T., Whitwell, R. L., \&amp; Goodale, M. A. (2015). The two-visual-systems hypothesis and the perspectival features of visual experience. Consciousness and Cognition, 35, 225-233. doi:10.1016/j.concog.2015.03.005. Retrieved; 04/05/2018.
[73] Fang, F., \&amp; He, S. (2010). Cortical responses to invisible objects in human dorsal and ventral pathways. Journal of Vision, 5(8), 15-15. doi:10.1167/5.8.15. Retrieved; 09/04/2018.

[74] Azadbakht, H., Parkes, L. M., Haroon, H. A., Augath, M., Logothetis, N. K., Crespigny, A. D., Parker, G. J. (2015). Validation of High-Resolution Tractography AgainstIn VivoTracing in the Macaque Visual Cortex. Cerebral Cortex, 25(11), 4299-4309. doi:10.1093/cercor/bhu326. Retrieved; 12/05/2018.

[75] Merabet, L. B., Devaney, K. J., Bauer, C. M., Panja, A., Heidary, G., \&amp; Somers, D. C. (2016). Characterizing Visual Field Deficits in Cerebral/Cortical Visual Impairment (CVI) Using Combined Diffusion Based Imaging and Functional Retinotopic Mapping: A Case Study. Frontiers in Systems Neuroscience, 10. doi: 10.3389/fnsys.2016.00013. Retrieved; 09/05/2018.

[76] Pelekanos, V., Mur, M., \&amp; Storrs, K. R. (2016). Extracting Object Identity: Ventral or Dorsal Visual Stream? The Journal of Neuroscience, 36(24), 6368-6370. doi:10.1523/jneurosci.1102-16.2016. Retrieved; 07/07/2018.

[77] Gilaie-Dotan, S. (2016). Visual motion serves but is not under the purview of the dorsal pathway. Neuropsychologia, 89,378-392.

doi: 10.1016/j. neuropsychologia.2016.07.018. Retrieved; 08/06/2018

[78] Grigorian, A., Mcketton, L., \&amp; Schneider, K. A. (2016). Measuring Connectivity in the Primary Visual Pathway in Human Albinism Using Diffusion Tensor Imaging and Tractography. Journal of Visualized Experiments, (114). doi:10.3791/53759. Retrieved; 08/06/2018

[79] Hajiabadi, M., Samii, M., \&amp; Fahlbusch, R. (2016). A preliminary study of the clinical application of optic pathway diffusion tensor tractography in suprasellar tumor surgery: Preoperative, intraoperative, and postoperative assessment. Journal of Neurosurgery, 125(3), 759-765.doi:10.3171/2015.6.jns1546. Retrieved; 10/06/2018.

[80] Aguirre, G. K., Datta, R., Benson, N., Prasad, S., Jacobson, S. G., Cideciyan, A. V., . . Gennatas, E.(2016). 
Patterns of individual variation in visual pathway structure and function in the sighted and blind. doi: 10.1101/065441. Retrieved; 12/05/2018.

[81] Sheth, B. R., \&amp; Young, R. (2016). Two Visual Pathways in Primates Based on Sampling of Space: Exploitation and Exploration of Visual Information. Frontiers in Integrative Neuroscience, 10. doi:10.3389/fnint.2016.00037. Retrieved; 17/05/2018.

[82] Rokem, A., Takemura, H., Bock, A. S., Scherf, K. S., Behrmann, M., Wandell, B. A., ... Pestilli, F.(2017). The visual white matter: The application of diffusion MRI and fiber tractography to vision science. Journal of Vision, 17(2), 4. doi:10.1167/17.2.4. Retrieved; 13/06/2018.

[83] Essayed, W. I., Zhang, F., Unadkat, P., Cosgrove, G. R., Golby, A. J., \&amp; Odonnell, L. J. (2017). White matter tractography for neurosurgical planning: A topography-based review of the current state of the art. NeuroImage: Clinical, 15, 659-672. doi:10.1016/j.nicl.2017.06.011. Retrieved; 10/06/2018.

[84] Simic, N., \&amp; Rovet, J. (2016). Dorsal and ventral visual streams: Typical and atypical development. Child Neuropsychology, 23(6), $678-691$. doi:10.1080/09297049.2016.1186616. Retrieved; 06/05/2018.

[85] Agarwal, V., Malcolm, J. G., Pradilla, G., \&amp; Barrow, D. L. (2017). Tractography for Optic Radiation Preservation in Transcortical Approaches to Intracerebral Lesions. Cureus. doi:10.7759/cureus.1722. Retrieved; $12 / 06 / 2018$.

[86] Freud, E., Culham, J., Plaut, D., \&amp; Behrmann, M. (2017). The large-scale organization of object processing in the ventral and dorsal pathways. Journal of Vision, 17(10), 286. doi: 10.1167/17.10.286. Retrieved; 05/05/2018.

[87] Hales, P. W., Smith, V., Dhanoa-Hayre, D., Ohare, P., Mankad, K., Darco, F., ... Clark, C. (2018). Delineation of the visual pathway in paediatric optic pathway glioma patients using probabilistic tractography, and correlations with visual acuity. NeuroImage: Clinical, 17, 541-548. doi:10.1016/j.nicl.2017.10.010. Retrieved; 17/05/2018.
[88] Zhan, M., Goebel, R., \&amp; Gelder, B. D. (2018). Ventral and Dorsal Pathways Relate Differently to Visual Awareness of Body Postures under Continuous Flash Suppression. Eneuro, 5(1).doi:10.1523/eneuro.0285-17.201 7. Retrieved; 09/06/2018. 